\title{
Simulation of the isotopic composition of stratospheric water vapour - Part 1: Description and evaluation of the EMAC model
}

\author{
R. Eichinger ${ }^{1}$, P. Jöckel ${ }^{1}$, S. Brinkop ${ }^{1}$, M. Werner ${ }^{2}$, and S. Lossow ${ }^{3}$ \\ ${ }^{1}$ Deutsches Zentrum für Luft- und Raumfahrt e.V. (DLR), Institut für Physik der Atmosphäre, Münchner Straße 20, \\ Oberpfaffenhofen, 82234 Weßling, Germany \\ ${ }^{2}$ Alfred Wegener Institute, Helmholtz Centre for Polar and Marine Research, Section Paleoclimate Dynamics, \\ Bussestrasse 24, 27570 Bremerhaven, Germany \\ ${ }^{3}$ Karlsruhe Institute of Technology, Institute for Meteorology and Climate Research, Hermann-von-Helmholtz-Platz 1, \\ 76344 Leopoldshafen, Germany \\ Correspondence to: R. Eichinger (roland.eichinger@dlr.de)
}

Received: 7 August 2014 - Published in Atmos. Chem. Phys. Discuss.: 16 September 2014

Revised: 18 April 2015 - Accepted: 25 April 2015 - Published: 21 May 2015

\begin{abstract}
This modelling study aims at an improved understanding of the processes that determine the water vapour budget in the stratosphere by means of the investigation of water isotope ratios. An additional (and separate from the actual) hydrological cycle has been introduced into the chemistry-climate model EMAC, including the water isotopologues $\mathrm{HDO}$ and $\mathrm{H}_{2}{ }^{18} \mathrm{O}$ and their physical fractionation processes. Additionally an explicit computation of the contribution of methane oxidation to $\mathrm{H}_{2} \mathrm{O}$ and $\mathrm{HDO}$ has been incorporated. The model expansions allow detailed analyses of water vapour and its isotope ratio with respect to deuterium throughout the stratosphere and in the transition region to the troposphere. In order to assure the correct representation of the water isotopologues in the model's hydrological cycle, the expanded system has been evaluated in several steps. The physical fractionation effects have been evaluated by comparison of the simulated isotopic composition of precipitation with measurements from a ground-based network (GNIP) and with the results from the isotopologue-enabled general circulation model ECHAM5-wiso. The model's representation of the chemical HDO precursor $\mathrm{CH}_{3} \mathrm{D}$ in the stratosphere has been confirmed by a comparison with chemical transport models (1-D, CHEM2D) and measurements from radiosonde flights. Finally, the simulated stratospheric HDO and the isotopic composition of water vapour have been evaluated, with respect to retrievals from three different satellite instruments (MIPAS, ACE-FTS, SMR). Discrepancies in stratospheric water vapour isotope ratios between two of the three satellite retrievals can now partly be explained.
\end{abstract}

\section{Introduction}

Some $30 \%$ of the temperature change since 1980 can be attributed to the radiative forcing of increased stratospheric water vapour (Solomon et al., 2010) and $10 \%$ of the global total ozone decline from 1960 to 1999 can be explained by the water vapour increase (Stenke and Grewe, 2005). However, the mechanisms driving long-term changes in stratospheric water vapour are not well understood (Füglistaler et al., 2009). Stratospheric water vapour is determined by in situ methane oxidation and the intrusion of water vapour through the tropical tropopause layer (TTL). The seasonal cycle of lower stratospheric water vapour in the Tropics is characterized by the tape recorder (Mote et al., 1996), which exhibits a hydrated lower stratosphere in boreal summer and fall and a dry lower stratosphere in boreal winter and spring. Thus, most of the water vapour enters the stratosphere during boreal summer when the tropopause temperatures are higher and monsoon systems (e.g. Gettelman and Kinnison, 2004) as well as enhanced deep convection over the Tropics (e.g. Khaykin et al., 2009) cause augmented transport of water vapour into the TTL. The contribution of the individual mechanisms to the overall budget of stratospheric water vapour, however, is poorly quantified.

The application of water isotopologues in tracer studies has the potential to answer open questions concerning the stratospheric water vapour budget. The different vapour pressures and binding energies of the respective water isotopologues lead to fractionation effects during phase transitions and chemical reactions. The individual processes, which con- 
trol the water vapour budget in the stratosphere, thus leave an isotopic fingerprint in the respective water vapour compound (Johnson et al., 2001). Direct injection of ice into the stratosphere through deep convection, dehydration of air during ascent by in situ formation of cirrus clouds and the in-mixing of older stratospheric air lead to an offset of the isotope ratios in the upper troposphere and lower stratosphere (UTLS) from simple Rayleigh distillation (see Steinwagner et al., 2010). The mechanisms which are responsible for the intrusion of water vapour into the stratosphere can hence be separated through the isotopic signature.

Recent satellite retrievals from three different instruments (SMR, MIPAS, ACE-FTS, see Urban et al., 2007; Steinwagner et al., 2007; Nassar et al., 2007) allow to obtain a global picture of the water isotopologue $\mathrm{HDO}$ and the water vapour isotope ratio $\delta \mathrm{D}\left(\mathrm{H}_{2} \mathrm{O}\right)$ - where $\delta \mathrm{D}\left(\mathrm{H}_{2} \mathrm{O}\right)=$ $\left(\frac{[\mathrm{HDO}] /\left[\mathrm{H}_{2} \mathrm{O}\right]}{R_{\mathrm{VSMOW}}}-1\right) \cdot 1000 ; R_{\mathrm{VSMOW}}=155.76 \times 10^{-6}$, Hagemann et al. (1970); VSMOW: Vienna Standard Mean Ocean Water, IAEA (2009) - in the stratosphere and in the transition region to the troposphere. In some regions the different satellite retrievals, however, show considerable deviations when comparing profiles and annual cycles of HDO mixing ratios and isotope ratios, respectively (Lossow et al., 2011). Furthermore, Steinwagner et al. (2010) found a tape recorder signal in $\delta \mathrm{D}\left(\mathrm{H}_{2} \mathrm{O}\right)$ in the tropical stratosphere in the MIPAS observations, comparable to the known tape recorder in water vapour mixing ratios. In contrast, Randel et al. (2012) did not find an analogue upward propagation of the seasonal cycle of water vapour isotope ratios in the stratosphere when analysing ACE-FTS data. Speculations about this discrepancy mainly focus on the different sampling techniques and retrieval algorithms. Consequently, in order to improve the understanding of the basic structure of $\delta \mathrm{D}\left(\mathrm{H}_{2} \mathrm{O}\right)$ in the stratosphere, comprehensive modelling of the physical and chemical isotope processes in a well-resolved global chemistry climate model (CCM) with explicit stratospheric dynamics is necessary.

Hitherto, a GCM (general circulation model) study by Schmidt et al. (2005) including HDO and focusing on the UTLS region only featured a relatively coarse vertical resolution in the stratosphere and only a prescribed tendency for chemical influences on HDO. Here, the water isotopologue HDO is implemented into the EMAC (ECHAM MESSy Atmospheric Chemistry; MESSy: Modular Earth Submodel System) model (Jöckel et al., 2005, 2010). EMAC provides the opportunity to accurately analyse tropospherestratosphere exchange processes on a global scale. When used with 90 layers in the vertical, its base model (ECHAM5; Roeckner et al., 2003) possesses a well-resolved tropopause region (the vertical resolution near the tropopause is about $500 \mathrm{~m}$; see Jöckel et al., 2006) and explicit stratospheric dynamics. Moreover, EMAC optionally represents chemical processes, which are needed for the computation of methane oxidation, which is crucial for the representation of $\mathrm{H}_{2} \mathrm{O}$ and HDO in the stratosphere.

Confirmation of the correct representation of the fractionation processes during phase transitions in EMAC is achieved through the evaluation of the isotope ratios in precipitation. The consideration of the influence of methane oxidation on atmospheric HDO requires the computation of the methane isotopologue $\mathrm{CH}_{3} \mathrm{D}$. In a next step, this tracer is evaluated with respect to chemical transport models (1-D, CHEM2D, Ridal et al., 2001; Ridal and Siskind, 2002) and measurements from stratospheric balloon flights (Röckmann et al., 2011). Finally, the HDO mixing ratios and $\delta \mathrm{D}\left(\mathrm{H}_{2} \mathrm{O}\right)$ in the stratosphere are compared with the observations from satellites. This approach yields a more complete picture of the isotopic composition of stratospheric water vapour and provides insights into the discrepancies between the respective satellite retrievals. Comprehensive analyses of stratospheric $\delta \mathrm{D}\left(\mathrm{H}_{2} \mathrm{O}\right)$ in EMAC will be presented in the companion part 2 paper (Eichinger et al., 2015). These model results will be investigated with respect to the sensitivity and the origin of the $\delta \mathrm{D}\left(\mathrm{H}_{2} \mathrm{O}\right)$ tape recorder, and the role of convective ice lofting on the pattern is analysed.

\section{Model description and simulation setup}

The MESSy submodel H2OISO ( $\mathrm{H}_{2} \mathrm{O}$ ISOtopologues) has been incorporated into the EMAC model system. This submodel comprises tracers (see Jöckel et al., 2008) for the three stable water isotopologues $\mathrm{H}_{2}^{16} \mathrm{O}$ ("normal" water, hereafter denoted as $\mathrm{H}_{2} \mathrm{O}$ ), $\mathrm{H}_{2}{ }^{18} \mathrm{O}$ and $\mathrm{HDO}$ for all three phases (vapour, liquid and ice), respectively. Moreover, it contains an additional hydrological cycle, identical to the model's actual hydrological cycle, which includes all processes that modify the tracers and the corresponding fractionation effects for the isotopologues during phase transitions. The modular approach of MESSy allows the optional usage of the H2OISO submodel for all users in future EMAC versions. Besides this structural difference, the implementation of the water isotopologues follows previous studies with ECHAM3 (Hoffmann et al., 1998), ECHAM4 (Werner et al., 2001) and ECHAM5 (Werner et al., 2011). Supplementary to these previous studies, the chemical fractionation effects during the formation of water vapour through methane oxidation are considered. Since observations of water isotopologues in the stratosphere are mostly available for $\mathrm{H}_{2} \mathrm{O}$ and $\mathrm{HDO}$, the more elaborate accounting for the chemical fractionation of $\mathrm{H}_{2}{ }^{18} \mathrm{O}$ was not conducted in this study. Hence, here $\mathrm{H}_{2}{ }^{18} \mathrm{O}$ basically only serves the evaluation of the model in the troposphere. The physical isotope effects of $\mathrm{HDO}$ and $\mathrm{H}_{2}{ }^{18} \mathrm{O}$ only differ by the corresponding fractionation factors. 


\subsection{Water isotopologues in the hydrological cycle of EMAC}

The hydrological cycle in the H2OISO submodel reproduces the actual hydrological cycle of the EMAC model. The tracers for $\mathrm{H}_{2} \mathrm{O}$ in the gaseous $\left(\mathrm{H}_{2} \mathrm{O}_{\text {vap }}\right)$, the liquid $\left(\mathrm{H}_{2} \mathrm{O}_{\text {liq }}\right)$ and the ice $\left(\mathrm{H}_{2} \mathrm{O}_{\text {ice }}\right)$ phase were tested to be equal to the standard ECHAM variables for the water vapour $(Q)$, the liquid water (XL) and the ice water (XI) content, respectively. Small numerical errors (the maxima are of the order of $10^{-20} \mathrm{~kg} \mathrm{~kg}^{-1} \mathrm{~s}^{-1}$ for water vapour and $10^{-22} \mathrm{~kg} \mathrm{~kg}^{-1} \mathrm{~s}^{-1}$ for liquid water and ice), which arise due to the coding design, are corrected after each time step, in order to prevent the two hydrological cycles from diverging. Moreover, we assured that these numerical errors are small enough to not deteriorate the calculation of the water isotopologues.

For the water isotopologues, fractionation effects occur during phase changes. Equilibrium and kinetic fractionation during the evaporation of water from oceans is described by the bulk formula of Hoffmann et al. (1998). The surface flux for the water isotopologues depends on the isotope ratio of the ocean, the wind speed above the surface, the sea surface temperature, the specific humidity and the isotopic composition of the vapour above the surface (Hoffmann et al., 1998). As in the study by Werner et al. (2011), the isotope ratio of the ocean is prescribed with a global gridded data set based on the ${ }^{18} \mathrm{O}$ isotopic composition in sea water by LeGrande and Schmidt (2006). Since there is no equivalent data set for the deuterium isotopic composition, the HDO content is prescribed as eight times the $\mathrm{H}_{2}{ }^{18} \mathrm{O}$ isotope ratios. This is in accordance with global observations (Craig and Gordon, 1965). Due to the limitations of the applied land surface scheme in the EMAC model, we neglect any isotope fractionation from land surfaces. The land surface scheme in EMAC is identical to the scheme in the ECHAM5 model. A more detailed description of this simplification is given in Werner et al. (2011). As for water vapour, liquid water and ice in the actual hydrological cycle, the advection of the new water isotopologue tracers follows the flux form semi-Lagrangian (FFSL) scheme by Lin and Rood (1996).

The cloud and convection parameterisations (CLOUD and CONVECT) in EMAC include a number of phase transitions and therefore several different fractionation effects. Again, the implementation follows the study of Werner et al. (2011). During the formation of clouds, condensation of water vapour to liquid water and deposition of vapour to cloud ice take place. For condensation within clouds, a closed system is assumed. The condensate is assumed to be in contact, and hence in isotopic equilibrium, with the surrounding vapour during the entire process. This also applies for the evaporation of cloud water, where, in contrast to evaporation from the ocean, a closed system is assumed. An open system is used for the deposition of water vapour to ice. Due to the low diffusivities of the isotopologues in the ice phase, no exchange happens between ice and vapour. The effective fractionation factor $\alpha_{\text {eff }}$ is used here, including a function for the supersaturation $S$. Werner et al. (2011) adjusted this function to $S=1.01-0.0045 \cdot T_{\text {cond }}$ (with $T_{\text {cond }}$ as the condensation temperature during ice crystal formation, given in ${ }^{\circ} \mathrm{C}$ ), in order to attain realistic isotope ratios in Antarctic snow. Since the focus of the present study lies on the tropopause region, where also low temperatures have a major effect on kinetic fractionation through deposition, as a first estimate, the values from Werner et al. (2011) have been taken. During the melting of ice and the freezing of water, no fractionation is assumed. Other in-cloud processes like sedimentation of ice, autoconversion, accretion and aggregation include no fractionation effects either. The isotopic (non-)equilibrium factor $\alpha_{\text {eff }}$, which describes a fractionation process between a falling raindrop and the surrounding water vapour, may vary with time. Its value depends on the humidity, the temperature, the diffusivity of the water molecules and the droplet size. Since these processes are not resolved in GCMs, the fractionation during re-evaporation of raindrops falling through undersaturated air can only be approximated. Following Hoffmann et al. (1998), an isotopical equilibration of $45 \%$ is assumed for large drops from convective rain and $95 \%$ for small drops falling from stratiform clouds. Due to their low exchange rates, snow and ice do not re-equilibrate at all, which leads to more depleted isotope ratios in solid precipitation.

\subsection{Stratospheric isotope chemistry for water and methane}

The EMAC model contains the submodel $\mathrm{CH} 4$, which provides a simplified methane oxidation mechanism to take into account the chemical production of water vapour. It includes a tracer for methane (the $\mathrm{CH}_{4}$ tracer), which experiences a source from the surface - here as lower boundary conditions from the submodel TNUDGE, see next section; alternatively as methane fluxes, provided by the submodel OFFEMIS (see Jöckel et al., 2010) - and a sink in form of methane oxidation. Solutions are calculated for the four oxidation reactions, which are determined by the mixing ratios of the three oxidation partners $\left(\mathrm{Cl}, \mathrm{OH}, \mathrm{O}\left({ }^{1} \mathrm{D}\right)\right)$ and the photolysis rate. The photolysis rate $j_{\mathrm{CH}_{4}}\left(=r_{h v}\right)$ is here calculated in the MESSy submodel JVAL (for details, see Landgraf and Crutzen, 1998; Sander et al., 2014) and passed on to the submodel CH4 (alternatively it can be prescribed). The rates for the oxidation of methane with the reaction partners $\mathrm{Cl}, \mathrm{OH}$ and $\mathrm{O}\left({ }^{1} \mathrm{D}\right)$ are calculated within the submodel $\mathrm{CH} 4$. First, the first-order reaction coefficients $k_{\mathrm{OH}}$ for $\mathrm{OH}, k_{\mathrm{Cl}}$ for $\mathrm{Cl}$ and $k_{\mathrm{O}^{1} \mathrm{D}}$ for $\mathrm{O}\left({ }^{1} \mathrm{D}\right)$ are determined. While $k_{\mathrm{O}^{1} \mathrm{D}}=1.75 \times 10^{-10} \mathrm{~cm}^{3} \mathrm{~s}^{-1}$ is constant, $k_{\mathrm{OH}}$ and $k_{\mathrm{Cl}}$ are temperature ( $T$ in $\mathrm{K}$ ) dependent and are computed by 


$$
\begin{aligned}
k_{\mathrm{OH}}= & 1.85 \times 10^{-20} . \\
& \exp \left(2.82 \cdot \log (T)-\frac{987}{T}\right) \mathrm{cm}^{3} \mathrm{~s}^{-1}
\end{aligned}
$$

and

$k_{\mathrm{Cl}}=6.6 \times 10^{-12} \cdot \exp \left(-\frac{1240}{T}\right) \mathrm{cm}^{3} \mathrm{~s}^{-1}$.

Subsequently the pseudo first-order rate coefficients for the reactions with methane are

$r_{\mathrm{O}^{1} \mathrm{D}}=k_{\mathrm{O}^{1} \mathrm{D}} \cdot c_{\mathrm{air}} \cdot \mathrm{O}\left({ }^{1} \mathrm{D}\right)$

$r_{\mathrm{Cl}}=k_{\mathrm{Cl}} \cdot c_{\mathrm{air}} \cdot \mathrm{Cl}$

$r_{\mathrm{OH}}=k_{\mathrm{OH}} \cdot c_{\mathrm{air}} \cdot \mathrm{OH}$,

with $\mathrm{O}\left({ }^{1} \mathrm{D}\right), \mathrm{Cl}$ and $\mathrm{OH}$ representing the prescribed mixing ratios (in $\mathrm{mol} \mathrm{mol}^{-1}$ ) of the respective species and $c_{\text {air }}$ the concentration of dry air molecules (in $\mathrm{cm}^{-3}$ ), which is calculated by

$c_{\mathrm{air}}=\frac{N_{\mathrm{A}} \times 10^{-6} \cdot p}{R_{\mathrm{gas}} \cdot T \cdot\left[1+\left(\frac{M_{\mathrm{air}}}{M_{\mathrm{H}_{2} \mathrm{O}}}-1\right) \cdot Q\right]}$.

Here $N_{\mathrm{A}}$ denotes the Avogadro constant $(6.022045 \times$ $10^{23} \mathrm{~mol}^{-1}$ ), $p$ the pressure (in Pa), $R_{\text {gas }}$ the universal gas constant $\left(8.314409 \mathrm{~J} \mathrm{~K}^{-1} \mathrm{~mol}^{-1}\right), T$ the temperature (in K), $M_{\text {air }}$ the molar mass of dry air $\left(28.97 \mathrm{~g} \mathrm{~mol}^{-1}\right), M_{\mathrm{H}_{2} \mathrm{O}}$ the molar mass of water $\left(18.02 \mathrm{~g} \mathrm{~mol}^{-1}\right)$ and $Q$ the specific humidity (in $\mathrm{kg} \mathrm{kg}^{-1}$ ).

The tendency for the methane tracer (in mol mol${ }^{-1} \mathrm{~s}^{-1}$ ) is then given by

$\frac{\partial\left(\mathrm{CH}_{4}\right)}{\partial t}=-1 \cdot \mathrm{CH}_{4} \cdot\left(r_{\mathrm{O}^{1} \mathrm{D}}+r_{\mathrm{Cl}}+r_{\mathrm{OH}}+r_{h v}\right)$,

where $\mathrm{CH}_{4}$ is the methane mixing ratio (in $\mathrm{mol} \mathrm{mol}^{-1}$ ) of the previous time step and the -1 accounts for the fact that this is a pure sink reaction for the methane tracer. To calculate the tendency for the specific humidity due to methane oxidation,

$$
\left.\frac{\partial Q}{\partial t}\right|_{C}=\frac{-2 \cdot \frac{\partial\left(\mathrm{CH}_{4}\right)}{\partial t}}{\frac{M_{\mathrm{air}}}{M_{\mathrm{H}_{2} \mathrm{O}}}\left(\frac{1}{1-Q}\right)^{2}}
$$

is applied. The subscript $C$ denotes that this is the chemical tendency of $Q$. This division is to convert the tendency from mol mol ${ }^{-1} \mathrm{~s}^{-1}$ to $\mathrm{kg} \mathrm{kg}^{-1} \mathrm{~s}^{-1}$. The negative sign here accounts for the fact that methane oxidation is a source for water vapour and the factor 2 for the reaction of the four hydrogen atoms of one methane molecule into two water molecules.

In order to take into account the chemical production of $\mathrm{HDO}$, analogously a parameterisation for the oxidation of
Table 1. Temperature-dependent kinetic isotope fractionation coefficients for the reaction with $\mathrm{CH}_{3} \mathrm{D}$. The kinetic isotope effect is determined by $\operatorname{KIE}(T)=A \cdot \exp (B / T)$ for the given temperature range (see Röckmann et al., 2011).

\begin{tabular}{lccc}
\hline Reactant & $T$ range & $A$ & $B$ \\
\hline $\mathrm{OH}$ & & 1.097 & $49 \pm 22$ \\
$\mathrm{O}\left({ }^{1} \mathrm{D}\right)$ & $224-295$ & 1.066 & 0 \\
$\mathrm{Cl}$ & $223-295$ & 1.278 & $51.31 \pm 19.1$ \\
\hline
\end{tabular}

$\mathrm{CH}_{3} \mathrm{D}$ has been devised. A tracer for $\mathrm{CH}_{3} \mathrm{D}$, the most abundant deuterium isotopologue of methane, was included for this purpose. The coefficients for the mass-dependent kinetic isotope effects (KIE) for the reactions of $\mathrm{CH}_{3} \mathrm{D}$ with $\mathrm{OH}$, $\mathrm{O}\left({ }^{1} \mathrm{D}\right)$ and $\mathrm{Cl}$ have been determined in laboratory measurements by Saueressig et al. $(1996,2001)$. They are partly temperature dependent and can be described with the function $\operatorname{KIE}(T)=A \cdot \exp (B / T)$. The values for $A$ and $B$ and their temperature ranges are given in Table 1 (see also Röckmann et al., 2011).

The absorption cross-section of $\mathrm{CH}_{3} \mathrm{D}$ is shifted $0.9 \mathrm{~nm}$ blueward relative to $\mathrm{CH}_{4}$ (Nair et al., 2005). For the photodissociation of $\mathrm{CH}_{3} \mathrm{D}$, this results in the fractionation factor $\mathrm{KIE}_{h v}=0.995$ in the atmosphere of Mars (see also Nixon et al., 2012). This approach is here applied to the Earth's atmosphere, since the photodissociation characteristics of methane do not differ from one planet of the solar system to another.

As for physical kinetic fraction processes, the Rayleigh equation

$R=R_{0}\left(\frac{N}{N_{0}}\right)^{\mathrm{KIE}^{-1}-1}$

is applied for the fractionation processes in the chemical reactions. Inserting the isotope ratios $\left(R_{0}\right.$ and $\left.R\right)$ and the total mixing ratios $\left(N_{0}\right.$ and $\left.N\right)$ before and after the reaction leads to

$$
\frac{\mathrm{CH}_{3} \mathrm{D}-\frac{\partial\left(\mathrm{CH}_{3} \mathrm{D}\right)}{\partial t}}{\mathrm{CH}_{4}-\frac{\partial\left(\mathrm{CH}_{4}\right)}{\partial t}}=\frac{\mathrm{CH}_{3} \mathrm{D}}{\mathrm{CH}_{4}}\left(\frac{\mathrm{CH}_{4}-\frac{\partial\left(\mathrm{CH}_{4}\right)}{\partial t}}{\mathrm{CH}_{4}}\right)^{\mathrm{KIE}^{-1}-1} .
$$

Using Eq. (7) for $\partial\left(\mathrm{CH}_{4}\right) / \partial t$ and considering that the KIE is different for each of the reactions, the tendency of the $\mathrm{CH}_{3} \mathrm{D}$ tracer is given by

$$
\begin{aligned}
& \frac{\partial\left(\mathrm{CH}_{3} \mathrm{D}\right)}{\partial t}=\mathrm{CH}_{3} \mathrm{D} . \\
& {\left[\left(1-\left(1+r_{\mathrm{OH}}\right)^{\mathrm{KIE}_{\mathrm{OH}}^{-1}}\right)+\left(1-\left(1+r_{\mathrm{Cl}}\right)^{\mathrm{KIE}_{\mathrm{Cl}}^{-1}}\right)+\right.} \\
& \left.\left(1-\left(1+r_{\mathrm{O}^{1} \mathrm{D}}\right)^{\mathrm{KIE}_{\mathrm{O}^{1} \mathrm{D}}^{-1}}\right)+\left(1-\left(1+r_{h v}\right)^{\mathrm{KIE}_{h v}^{-1}}\right)\right] .
\end{aligned}
$$

In order to calculate the tendency of the HDO tracer from the tendency of the $\mathrm{CH}_{3} \mathrm{D}$ tracer (i.e. the chemical tendency 
of HDO), analogously to Eq. (8),

$$
\left.\frac{\partial(\mathrm{HDO})}{\partial t}\right|_{C}=\frac{-1 \cdot \frac{\partial\left(\mathrm{CH}_{3} \mathrm{D}\right)}{\partial t}}{\frac{M_{\mathrm{air}}}{M_{\mathrm{HDO}}}\left(\frac{1}{1-\mathrm{HDO}}\right)^{2}}
$$

is applied. Here, we use the specific humidity and the molar mass of HDO $\left(M_{\mathrm{HDO}}=19.02 \mathrm{~g} \mathrm{~mol}^{-1}\right)$ instead of $Q$ and $M_{\mathrm{H}_{2} \mathrm{O}}$ and the factor 1 instead of 2, because the oxidation of one $\mathrm{CH}_{3} \mathrm{D}$ molecule can only produce one HDO molecule. This approach, however, neglects the intermediate reactions between $\mathrm{CH}_{3} \mathrm{D}$ and $\mathrm{HDO}$ with molecular hydrogen and its isotopologue $\mathrm{HD}$. While $\mathrm{H}_{2}$ is fairly constant throughout the stratosphere and therefore can be neglected for the $\mathrm{CH}_{4}$ conversion to $\mathrm{H}_{2} \mathrm{O}, \delta \mathrm{D}\left(\mathrm{H}_{2}\right)$ increases with altitude due to chemical isotope fractionation effects (see Röckmann et al., 2003; Rhee et al., 2006). Hence, some deuterium is stored in HD during this process and therefore one $\mathrm{CH}_{3} \mathrm{D}$ molecule translates into a little less than exactly one HDO molecule (see also Rahn et al., 2003). In order to account for this, we apply the stratospheric relation

$\mathrm{HD}=-6.32 \times 10^{-5} \cdot \mathrm{CH}_{4}+0.297$

derived from measurements by McCarthy et al. (2004). The time derivative of HD in dependence of the time derivative of $\mathrm{CH}_{4}$ can now be used to account for the stored deuterium in HD and thus for the reduction of chemically formed HDO. Therefore, Eq. (12) was extended to

$$
\left.\frac{\partial(\mathrm{HDO})}{\partial t}\right|_{C}=\frac{-\frac{\partial\left(\mathrm{CH}_{3} \mathrm{D}\right)}{\partial t}+6.32 \times 10^{-5} \cdot \frac{\partial\left(\mathrm{CH}_{4}\right)}{\partial t}}{\frac{M_{\mathrm{air}}}{M_{\mathrm{HDO}}}\left(\frac{1}{1-\mathrm{HDO}}\right)^{2}} .
$$

This approach still neglects a number of effects that may be important for the chemical production of HDO: firstly, the other, rather rare methane isotopologues $\mathrm{CH}_{2} \mathrm{D}_{2}, \mathrm{CHD}_{3}$ and $\mathrm{CD}_{4}$ as well as the reaction partner OD (an isotopologue of the hydroxyl radical) are not considered. Secondly, the fractionation effects during the formation of HDO by HD are not taken into consideration. Most of these, however, are poorly quantified (Zahn et al., 2006) and therefore neglected for this initial study. These simplifications have to be kept in mind when evaluating the model results in the stratosphere.

Emissions of $\mathrm{CH}_{3} \mathrm{D}$ could be defined with the aid of an extension (for deuterium) of the MESSy isotope scheme of Gromov et al. (2010). However, this task requires the integration of the full chemistry scheme and therefore goes beyond the scope of our study, which mainly focuses on stratospheric and upper tropospheric processes. This leads to another simplification: in accordance with Rhee et al. (2006) the isotope ratio of methane was fixed to $-86 \%$ in the troposphere (i.e. here, below $500 \mathrm{hPa}$ ). This is in between the stratospheric entry values of $\delta \mathrm{D}\left(\mathrm{CH}_{4}\right)$ (the $\delta \mathrm{D}\left(\mathrm{CH}_{4}\right)$ is also based on VSMOW) found by Rahn et al. (2003) (-90\%), Röckmann et al. (2003) (-80\%o) and Röckmann et al. (2011) $(-81 \%)$ and also within the range of recent aircraft measurements presented by Umezawa et al. (2012).

\subsection{Simulation setup}

For this study, an EMAC (v2.42) model simulation in T42L90MA resolution was performed. This corresponds to an approximate horizontal grid box size of $2.8^{\circ} \times 2.8^{\circ}, 90$ layers in the vertical and explicitly resolved stratospheric dynamics. The uppermost model layer is centred around $0.01 \mathrm{hPa}$. The MESSy submodels which were applied in this simulation (in addition to the described H2OISO and $\mathrm{CH} 4$ submodels and the ECHAM5 base model from EMAC version 2.42) are listed and described in the Appendix. The time step of the simulation was $12 \mathrm{~min}$ and the output was set to produce instantaneous values with an interval of $11 \mathrm{~h}$. The EMAC model provides the possibility to use several different convection schemes. In all the simulations conducted for this study, the "Tiedtke-Nordeng" convection scheme (Tiedtke, 1989; Nordeng, 1994) was applied. Before starting the actual simulation, a 20-year free-running simulation was carried out to obtain steady-state initial values for water, methane and their isotopologues. From these initial conditions a simulation with specified dynamics (i.e. in "nudged" mode) was started, which means a Newtonian relaxation of the divergence, the vorticity, the temperature and the logarithm of the surface pressure towards reference data. Here, the relaxation is performed up to $1 \mathrm{hPa}$ towards the ERA-INTERIM reanalysis data (ECMWF; Dee et al., 2011). This guarantees that not only the climatic state, but also the meteorological situation of the model simulation corresponds to the actual states and allows a direct comparison of the model results with satellite or in situ measurements. The simulation starts at the beginning of the year 1982 and terminates at the end of the year 2010. From the steady-state conditions, which are used for the initialisation, the model again needs several years to adjust to the conditions of the "nudged" mode. The first 8 years are hence not considered for the analysis. Only the 21 years from 1990 to 2010 are evaluated. Transient greenhouse gas concentrations are prescribed throughout the atmosphere. Methane is prescribed at the lower boundary through the submodel TNUDGE, based on observations. The mixing ratios of $\mathrm{OH}, \mathrm{Cl}, \mathrm{O}\left({ }^{1} \mathrm{D}\right)$ are prescribed (monthly averages) from a previous "nudged", transient EMAC simulation with full chemistry. The same applies for ozone, which is needed to calculate the photolysis rate in the submodel JVAL. As mentioned above, the methane oxidation is calculated in the CH4 submodel.

\section{Model evaluation}

Before evaluating the model simulation with respect to the isotopic composition of water vapour in the stratosphere, we show that the basis for this is established in the EMAC model. This includes the correct representation of the physical water isotope effects in the troposphere and the chemical $\mathrm{HDO}$ precursor $\mathrm{CH}_{3} \mathrm{D}$ in the stratosphere, as well as its sink 
reactions. Subsequently stratospheric HDO mixing ratios and $\delta \mathrm{D}\left(\mathrm{H}_{2} \mathrm{O}\right)$ are compared to satellite observations.

\subsection{Water isotope ratios in precipitation}

The isotopic composition in precipitation makes it possible to evaluate various isotope fractionation effects (Dansgaard, 1964). Hence, the representation of the isotope physics in the model can be evaluated by examining the isotope ratios in precipitation. This has been conducted in many studies with isotopologue-enabled GCMs (e.g. Risi et al., 2010; Werner et al., 2011).

The GNIP (Global Network of Isotopes in Precipitation) measurement survey provides a comprehensive database for this purpose. The International Atomic Energy Agency (IAEA) and the World Meteorological Organisation (WMO) started GNIP in 1961. Since its start, more than 800 meteorological stations in 101 countries have collected samples of the water isotopologues $\mathrm{HDO}$ and $\mathrm{H}_{2}{ }^{18} \mathrm{O}$ in precipitation (IAEA, 2009). Some of these stations provided monthly precipitation measurements for several decades. Most of them, however, operated for a much shorter period. This data set serves as a basis for the evaluation of the simulated isotope ratios in the troposphere. Good qualitative agreement was achieved when comparing the general global patterns in annual mean precipitation, as well as in the seasonal cycles between GNIP and EMAC. Details can be found in the Supplement.

The isotopologue-enabled GCM ECHAM5-wiso (water isotopologues) has also been tested successfully against GNIP data, as well as against other water isotopologue measurements (see Werner et al., 2011). Several model resolutions have been applied for this study. The results of the lowest of these horizontal resolutions $\left(\mathrm{T} 31 \sim 3.75^{\circ} \times 3.75^{\circ}\right)$ was largely reproduced with the EMAC model (see Supplement). Since the model physics and dynamics of the two models, including the hydrological cycle and the implementation of the water isotopologues (as described in Sect. 2), are almost identical, this is not surprising. However, it is a prerequisite for assuring the correct representation of the tropospheric isotope composition of water. A detailed comparison between EMAC and ECHAM5-wiso is given in the Supplement. The good quantitative agreement of this comparison supports the conclusion, that the EMAC model with the H2OISO submodel represents the state of the art of GCMs with an explicit representation of the water isotopologues $\mathrm{HDO}$ and $\mathrm{H}_{2}{ }^{18} \mathrm{O}$ in the troposphere.

\section{2 $\mathrm{CH}_{3} \mathrm{D}$ in the stratosphere}

The simulated $\mathrm{CH}_{3} \mathrm{D}$ is compared to results from the 1-D model by Ridal et al. (2001) and the CHEM2D model by Ridal and Siskind (2002). These models comprise an oxidation scheme, where $\mathrm{CH}_{3} \mathrm{D}$ produces HDO through a number of chemical reactions. This oxidation scheme was devel-

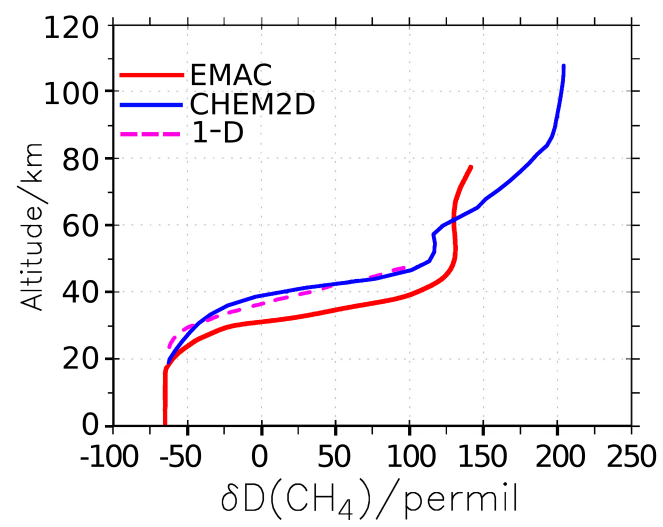

Figure 1. Comparison of equatorial averages of $\delta \mathrm{D}\left(\mathrm{CH}_{4}\right)$ with altitude between EMAC (red), CHEM2D (blue) by Ridal and Siskind (2002) and the 1-D model (dashed purple) by Ridal et al. (2001).

oped for the 1-D model. For the CHEM2D model, it was extended for higher altitudes and included into the Naval Research Laboratory 2-D chemical/dynamical model. In Ridal (2002) and Ridal and Siskind (2002) the two chemical transport models have shown good general agreement with measurements from the ATMOS (Atmospheric Trace MOlecule Spectroscopy) instrument (Irion et al., 1996). ATMOS provides global data for $\mathrm{CH}_{3} \mathrm{D}$ and $\mathrm{HDO}$. However, with large uncertainties. The equatorial values of $\delta \mathrm{D}\left(\mathrm{CH}_{4}\right)$ of EMAC, CHEM2D and the 1-D model are presented in Fig. 1.

The tropospheric values of $\delta \mathrm{D}\left(\mathrm{CH}_{4}\right)$ in the CHEM2D and the 1-D model are fixed to -68 and $-65 \%$, respectively. For a better comparison with these models, an additional EMAC simulation was carried out, with the only difference that this value was set from -86 to $-68 \%$ (see Sect. 2.2). Therefore, the model results do not differ below the tropopause. Moreover, the overall dependence of $\delta \mathrm{D}\left(\mathrm{CH}_{4}\right)$ on altitude qualitatively agrees in all the three model simulations. Between 20 and $50 \mathrm{~km}$ altitude the methane isotope ratio increases from $-68 \%$ to around $+120 \%$ in CHEM2D and the 1-D model, and to around $+130 \%$ in EMAC. Especially the increase in the lower stratosphere is much stronger in EMAC, which leads to rather large discrepancies in the altitude range between 30 and $40 \mathrm{~km}$. Between 50 and $60 \mathrm{~km}$, both CHEM2D and EMAC show almost no change in $\delta \mathrm{D}\left(\mathrm{CH}_{4}\right)$ with altitude, and the 1-D model does not extend above $50 \mathrm{~km}$. This is the transition region between the altitudes of the chemical and the photolytic methane oxidation. The photodissociation, which becomes important above $60 \mathrm{~km}$ and increases continuously above, is much stronger in CHEM2D. This is somewhat surprising, because there is no fractionation included for the photolysis of $\mathrm{CH}_{3} \mathrm{D}$ in the CHEM2D model. Even though the fractionation for photolysis in EMAC is very small, the photolysis of $\mathrm{CH}_{3} \mathrm{D}$ is expected to be of similar strength as in CHEM2D. The discrepancy is hence likely caused by the differences in the calculation of the photolysis rates in EMAC and CHEM2D. Since the mid of the upper- 
most layer of the EMAC model in the applied resolution is at $80 \mathrm{~km}$, a comparison further above is not possible.

Measurements of $\mathrm{CH}_{3} \mathrm{D}$ in the stratosphere are sparse. Röckmann et al. (2011), however, collected 13 altitude profiles from stratospheric balloon borne measurements, which were provided by the Max Planck Institute (MPI) for Solar System Research and by the Institute for Atmospheric and Environmental Sciences of the University of Frankfurt. The mixing ratios and the isotopic composition of $\mathrm{CH}_{4}$ were measured using a high-precision continuous-flow isotope ratio mass spectrometry system (Brass and Röckmann, 2010). Twelve of these balloon flights can be used for direct intercomparison with the data from the EMAC simulation. One flight (Flight ID: HYD-87-03) was conducted in 1987. Since the model results are considered to be in steady state only from 1990 on, this profile is not taken into account for the evaluation. In Fig. 2, 12 panels are presented showing the balloon-borne data and the EMAC results of $\delta \mathrm{D}\left(\mathrm{CH}_{4}\right)$ as function of altitude, between 5 and $35 \mathrm{~km}$. The flight IDs included in the panels provide information about the location, the month and the year of the balloon flights (see caption). To provide an estimate of the average and the annual variability of $\delta \mathrm{D}\left(\mathrm{CH}_{4}\right)$ in the model simulation, additionally the averages, maxima and minima of the 21 simulation years of the respective months at the location of the launch are included in the panels.

In general, a good qualitative agreement is achieved between the measured and the simulated data. Both simulation and measurements show an increase of the methane isotope ratios from tropospheric values to values between 100 and $200 \%$ at 25 to $35 \mathrm{~km}$ in the Arctic region and to values between 0 and $100 \%$ in the mid-latitude and tropical regions. The balloon-borne profiles are mostly lying within the extremes of the simulation and close to the simulated values from the same day and location. The measured $\delta \mathrm{D}\left(\mathrm{CH}_{4}\right)$ values in the troposphere and lower stratosphere are in good agreement with the chosen value of $-86 \%$ from the study by Rhee et al. (2006). The steep increase of $\delta \mathrm{D}\left(\mathrm{CH}_{4}\right)$ above $25 \mathrm{~km}$ in the simulation can only be seen in the measurements of the Arctic region (KIR). In the mid-latitude (GAP and ASA) profiles, the $\delta \mathrm{D}\left(\mathrm{CH}_{4}\right)$ increase with height is smaller, which leads to partly large deviations at these altitudes. The differences in the KIR-00-01 and the KIR-03-03 profiles between simulation and balloon flights are exceptional. Apart from the two uppermost data points in the KIR-03-03 profile, the measured $\delta \mathrm{D}\left(\mathrm{CH}_{4}\right)$ values are constantly higher than the simulated values. These two profiles are associated with special meteorological and thus chemical situations. The KIR03-03 data comprise a mesospheric enclosure and during the sampling of the KIR-00-01 data, a strong Arctic vortex was present (Röckmann et al., 2011). These phenomena can also be observed in the simulation - due to the "nudging" these special meteorological situations and the associated chemical situations are broadly represented. However, the horizontal resolution of the model simulation is too coarse to re- solve sharp horizontal gradients around the site of the balloon launch. Moreover, the balloon's drift off the launching site while ascending can cause deviations of such magnitudes. Also, this may be related to omitting the chemical cycle of $\mathrm{H}_{2}$ and $\mathrm{HD}$, since isotopically very heavy $\mathrm{H}_{2}$ might have been reconverted to $\mathrm{CH}_{4}$ in these profiles.

Another method for evaluating the methane isotope chemistry is assessing the relation of $\delta \mathrm{D}\left(\mathrm{CH}_{4}\right)$ to the $\mathrm{CH}_{4}$ mixing ratio. The $\delta \mathrm{D}\left(\mathrm{CH}_{4}\right)$ values of the same data as in Fig. 2, from 5 to $35 \mathrm{~km}$ altitude, are plotted versus the $\mathrm{CH}_{4}$ mixing ratios in Fig. 3. The figure is divided into the launches in the polar region (KIR) in the left panel and the launches in mid- (ASA, GAP) and tropical (HYD) latitudes in the right panel.

Again, overall consistency between the simulation and the measurements is visible. Apart from a single exception (the measurement from the HYD-99-04 profile, right panel) the simulated $\delta \mathrm{D}\left(\mathrm{CH}_{4}\right)$ as function of the methane mixing ratios agrees very well with the measurements. The slope of increasing isotope ratios with decreasing methane mixing ratios is almost identical. Since these compact tracer-tracer correlations are generally found for trace gases whose life times are longer than the transport times (Plumb and Ko, 2004), it implies that the chemical removal of the $\mathrm{CH}_{3} \mathrm{D}$ tracer in relation to the removal of the $\mathrm{CH}_{4}$ tracer is well represented, despite the simplified chemistry parameterisation.

\subsection{HDO in the stratosphere}

During the first decade of the 21st century, three satellite missions collected data applicable for the retrieval of the water isotopologue HDO in the stratosphere. The MIPAS (Michelson Interferometer for Passive Atmospheric Sounding) instrument on Envisat (Environmental Satellite) allowed the retrieval of HDO by measuring the thermal emission in the mid-infrared. This high-resolution Fourier transform spectrometer measured at the atmospheric limb and provided data for HDO retrievals in full spectral resolution from July 2002 to March 2004, roughly in the altitude range between 10 and $50 \mathrm{~km}$. It orbits the Earth sun-synchronously 14 times a day. The vertical resolution for the retrieval of HDO is around $5 \mathrm{~km}$ between the tropopause and $30 \mathrm{~km}$ altitude; above it degrades ( $\sim 8 \mathrm{~km}$ at $40 \mathrm{~km}$ ) (Steinwagner et al., 2007; Lossow et al., 2011). The Odin satellite also orbits the Earth sun-synchronously and carries the SMR (SubMillimetre Radiometer) instrument, among other purposes to passively measure HDO on the global scale roughly on 1 day per week. It operates in the microwave range. Data has been retrieved from the start of the mission in 2001 until today, at altitudes between roughly 20 and $70 \mathrm{~km}$ with a vertical resolution of around $3 \mathrm{~km}$ (Urban et al., 2007). The ACEFTS (Atmospheric Chemistry Experiment Fourier Transform Spectrometer) instrument circularly orbits the Earth on the SCISAT satellite and obtains Fourier transform absorption spectra from solar occultation measurements. It has a vertical resolution between 2 and $6 \mathrm{~km}$ and a comparably limited 

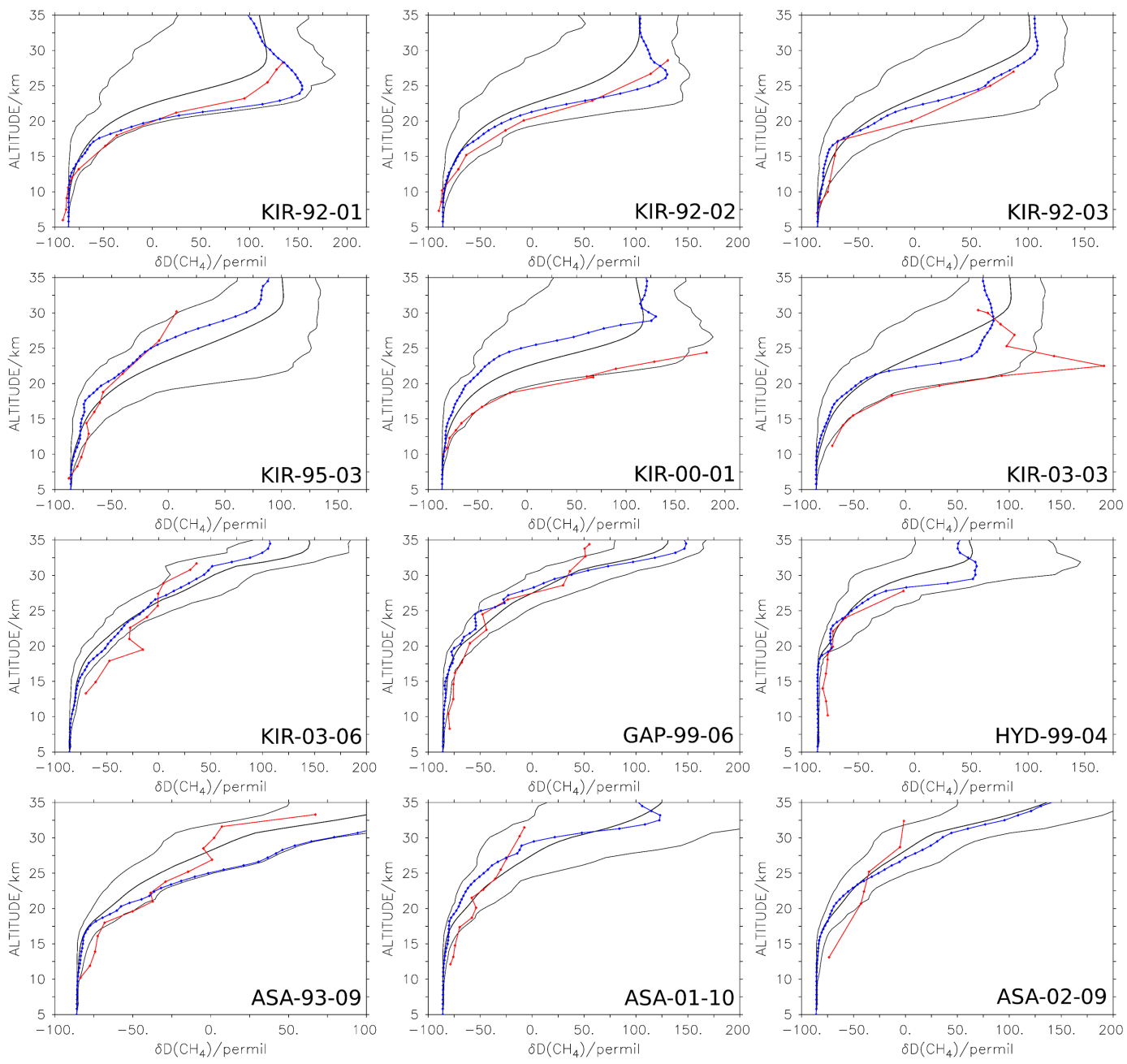

Figure 2. Comparison of $\delta \mathrm{D}\left(\mathrm{CH}_{4}\right)$ vertical profiles between EMAC and balloon-borne data by Röckmann et al. (2011). The red lines show the observations and the blue lines show the EMAC data of the same day at the location of the balloon launch. The black lines represent the simulated averages, minima and maxima of the 21 monthly averages of the respective month at the location of the balloon launch. The flight IDs included in the panels denote the location, the year and the month of the balloon flight. KIR: Kiruna, Sweden $\left(67.9^{\circ} \mathrm{N}, 21.10^{\circ} \mathrm{E}\right)$; GAP: Gap, France $\left(44.44^{\circ} \mathrm{N}, 6.14^{\circ} \mathrm{E}\right)$; HYD: Hyderabad, India $\left(17.5^{\circ} \mathrm{N}, 78.60^{\circ} \mathrm{E}\right)$; ASA: Aire sur l'Adour, France $\left(43.70^{\circ} \mathrm{N}, 0.30^{\circ} \mathrm{W}\right)$.

spatial sampling. The ACE orbit is optimised for measurements in mid- and high latitudes; the Tropics are only covered during the 4 months of February, April, August and October (Nassar et al., 2007; Randel et al., 2012).

Lossow et al. (2011) collected data of the three instruments for intercomparison and concluded a good consistency between MIPAS and ACE-FTS at altitudes above $20 \mathrm{~km}$. Below this altitude, issues like different cloud filtering and measurement techniques as well as different vertical resolutions cause large deviations. Generally, in the stratosphere the MIPAS and the ACE-FTS data agree favourably; the SMR data show considerably drier conditions, especially below $30 \mathrm{~km}$. This is mainly due to uncertainties in the different spectroscopies of the instruments (Lossow et al., 2011).

These data could now also be used to evaluate the HDO simulated by EMAC. In Fig. 4, the tropical $\left(15^{\circ} \mathrm{S}\right.$ to $\left.15^{\circ} \mathrm{N}\right)$
HDO mixing ratios of the three satellite instruments and the EMAC model are presented. Additionally to the data of MIPAS, SMR and version 2.2 of ACE-FTS shown by Lossow et al. (2011), here also version 3.0 of ACE-FTS is included, which reaches higher up in the stratosphere, compared to version 2.2. Since ACE-FTS only provides data for 4 months per year in this region, the panels show averages for February, April, August and October. Since the years of the ACE-FTS and the MIPAS satellite retrievals do not overlap, a direct comparison is not possible. However, tests have shown that the averages of the periods of the individual retrievals do not show substantial differences between each other and between the average of the entire simulation. In order to get a good estimate for the comparison of the model with all retrievals and for the annual variability, the averages, the minima and the maxima of the respective months have been taken from the 

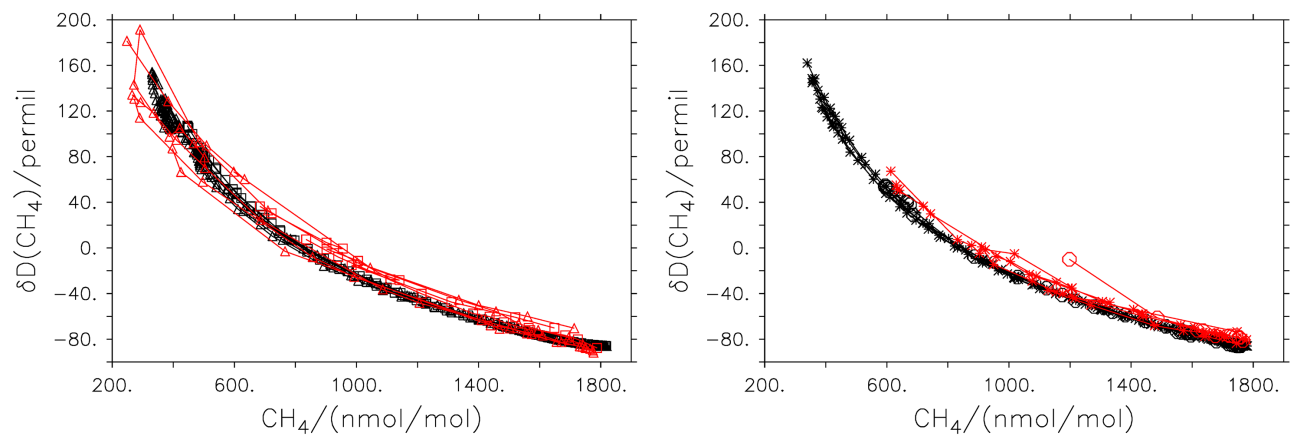

Figure 3. Comparison of the relations of $\delta \mathrm{D}\left(\mathrm{CH}_{4}\right)$ to $\mathrm{CH}_{4}$ between EMAC (black) and balloon-borne data (red; data as in Fig. 2). The left panel shows the Arctic data (KIR, $\triangle$ : vortex, $\square$ : non-vortex) and the right panel shows the mid-latitude (*) and tropical data (o). The altitude range is 5 to $35 \mathrm{~km}$.

entire 21 years of the EMAC simulation. Since, at first order, the HDO mixing ratios follow those of $\mathrm{H}_{2} \mathrm{O}$, the profiles of $\mathrm{H}_{2} \mathrm{O}$ of EMAC and of the mentioned satellite retrievals are shown in Fig. 5 in the same manner, in order to allow a more detailed discussion of the results.

The EMAC data are generally drier in $\mathrm{HDO}$ and in $\mathrm{H}_{2} \mathrm{O}$ compared to the MIPAS and the ACE-FTS profiles in each of the presented months at all altitudes. For water vapour in the UTLS, this offset has already been shown by Jöckel et al. (2006) and is consistent with the slightly too cold hygropause in the nudging data (see e.g. Liu et al., 2010). Only between 30 and $35 \mathrm{~km}$ do the $\mathrm{H}_{2} \mathrm{O}$ profiles of EMAC increase more strongly than in the satellite data and reach the level of ACE-FTS $\mathrm{H}_{2} \mathrm{O}$ mixing ratios. For HDO, this is not the case - its increase with height at these altitudes is rather similar between EMAC and the satellite retrievals and therefore the offset remains. In the altitude range between 16 and $30 \mathrm{~km}, \mathrm{HDO}$ in the EMAC simulation quantitatively corresponds well with the Odin retrieval. In this region also local maxima and minima, which can be seen in all four satellite profiles, are reproduced qualitatively in EMAC. These reveal the seasonal cycle of $\mathrm{HDO}$ and $\mathrm{H}_{2} \mathrm{O}$. Due to the spectral band that is used to derive these parameters by SMR, in this special case, $\mathrm{H}_{2} \mathrm{O}$ cannot be retrieved below $20 \mathrm{~km}$ while the limit for HDO is between 17 and $18 \mathrm{~km}$. Especially for April and August, the local HDO minimum between 25 and $30 \mathrm{~km}$ in the EMAC data is not as pronounced as in the satellite retrievals. Above the local minima the HDO mixing ratios of all satellite profiles increase strongly with altitude to values around $1.1 \mathrm{nmol} \mathrm{mol}^{-1}$ at $50 \mathrm{~km}$, while the EMAC simulation shows HDO mixing ratios of only $0.6 \mathrm{nmol} \mathrm{mol}^{-1}$ at these altitudes. $\mathrm{In}_{2} \mathrm{O}$, this behaviour is observable as well. However, only at altitudes above around $40 \mathrm{~km}$ and at a significantly smaller magnitude. Therefore, to some extent, this is most likely due to the assumptions made in the chemistry parameterisation for HDO, which does not include the influence of the fractionation effects during the reactions concerning molecular hydrogen. The simplified methane oxidation scheme itself, however, also plays a role here.

\subsection{The stratospheric $\delta \mathrm{D}$ tape recorder}

The tape recorder signal in $\mathrm{H}_{2} \mathrm{O}$, $\mathrm{HDO}$ and $\delta \mathrm{D}\left(\mathrm{H}_{2} \mathrm{O}\right)$ in the EMAC simulation is evaluated with respect to the MIPAS data. The satellite and the model data are compared in Fig. 6. The left panels show the EMAC results and the right panels show the MIPAS retrieval.

Overall, there is only a rather weak agreement between EMAC and MIPAS in all three quantities. As already shown in the previous section, a persistent (all altitudes, all seasons) dry bias in $\mathrm{H}_{2} \mathrm{O}$ and $\mathrm{HDO}$ is visible in the EMAC simulation. Also $\delta \mathrm{D}\left(\mathrm{H}_{2} \mathrm{O}\right)$ is generally too low throughout the stratosphere. In the lower stratosphere, some of these differences can be explained with the coarse vertical resolution of the MIPAS retrieval, which smoothes the hygropause (see Steinwagner et al., 2007). In the upper stratosphere, the underestimation by the model can be associated to the assumptions in the chemistry parameterisation. In the lower stratosphere, the strongest deviations in $\delta \mathrm{D}\left(\mathrm{H}_{2} \mathrm{O}\right)$ can be observed during Northern Hemisphere (NH) summer when MIPAS observations show $\delta \mathrm{D}\left(\mathrm{H}_{2} \mathrm{O}\right)$ values around $-500 \%$ and the $\delta \mathrm{D}\left(\mathrm{H}_{2} \mathrm{O}\right)$ values in EMAC do not exceed $-600 \%$. A tape recorder signal can be seen in all three quantities for both the model and observations, although with different amplitudes and a phase shift of 2-3 months. While the maxima of the tape recorder in the lower stratosphere in EMAC are found during summer, the satellite data show them at the beginning of autumn. This can partly (at maximum 1 month) be an artefact of the MIPAS retrieval and its coarse vertical sampling, but has to be kept in mind and compared with other data sets. The tape recorder signals in $\mathrm{HDO}$ and $\mathrm{H}_{2} \mathrm{O}$ fade out at around $30 \mathrm{~km}$ in both model and observations. The $\delta \mathrm{D}\left(\mathrm{H}_{2} \mathrm{O}\right)$ tape recorder signal in MIPAS reaches these altitudes as well, the EMAC $\delta \mathrm{D}\left(\mathrm{H}_{2} \mathrm{O}\right)$ tape recorder, in contrast, fades out somewhat lower.

The amplitude of the tape recorder in EMAC is larger for $\mathrm{H}_{2} \mathrm{O}$ and smaller for $\mathrm{HDO}$ and $\delta \mathrm{D}\left(\mathrm{H}_{2} \mathrm{O}\right)$, respectively, compared to the MIPAS data. Above $28 \mathrm{~km}$, the $\delta \mathrm{D}\left(\mathrm{H}_{2} \mathrm{O}\right)$ tape recorder becomes overshadowed by chemically pro- 

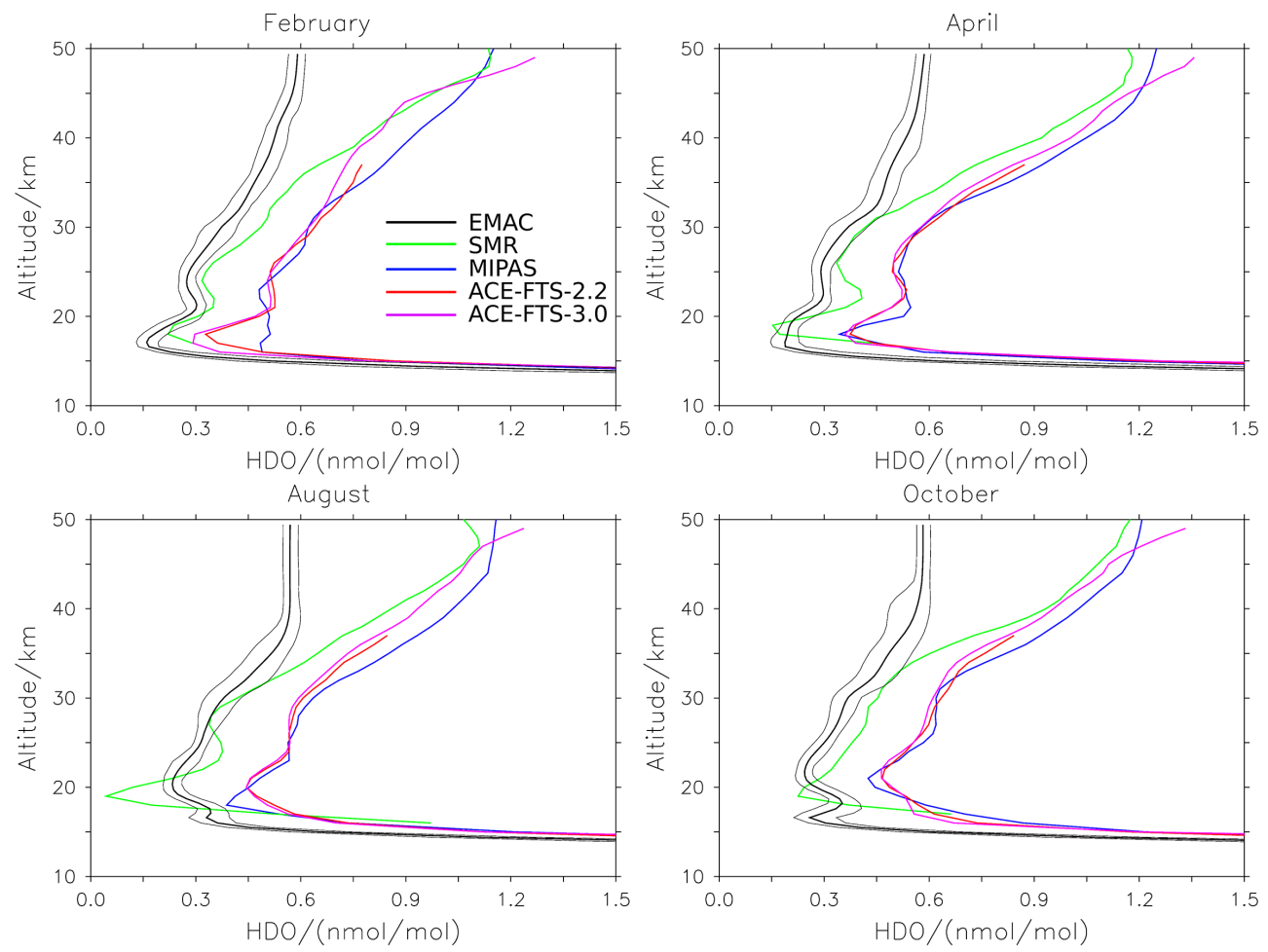

Figure 4. Comparison of HDO mixing ratio-altitude profiles between EMAC and various satellite observations. Black: averages, minima and maxima of 21 monthly averages of the EMAC simulation for the respective months; green: Odin/SMR; blue: ENVISAT/MIPAS; red: SCISAT/ACE-FTS-2.2; purple: SCISAT/ACE-FTS-3.0.

duced high $\delta \mathrm{D}\left(\mathrm{H}_{2} \mathrm{O}\right)$ values. This effect is further investigated in the companion part 2 paper (Eichinger et al., 2015). The MIPAS $\delta \mathrm{D}\left(\mathrm{H}_{2} \mathrm{O}\right)$ tape recorder might be amplified artificially by the offsets in vertical resolution between $\mathrm{H}_{2} \mathrm{O}$ and HDO (Orbe et al., 2013). A correction of this error is likely to reveal a $\delta \mathrm{D}\left(\mathrm{H}_{2} \mathrm{O}\right)$ tape recorder signal with smaller amplitude in the MIPAS retrieval.

By analysing ACE-FTS data, Randel et al. (2012) found a tape recorder signal in $\mathrm{H}_{2} \mathrm{O}$ and in $\mathrm{HDO}$, but could not find a corresponding pattern in $\delta \mathrm{D}\left(\mathrm{H}_{2} \mathrm{O}\right)$. The lower stratosphere in Fig. 7 of Randel et al. (2012) shows distinct seasonally varying maxima and minima of $\delta \mathrm{D}\left(\mathrm{H}_{2} \mathrm{O}\right)$; these, however, hardly propagate upwards in time. For comparison with the ACE-FTS data, the tropical $\mathrm{H}_{2} \mathrm{O}, \mathrm{HDO}$ and $\delta \mathrm{D}\left(\mathrm{H}_{2} \mathrm{O}\right)$ in the stratosphere of the EMAC simulation are displayed in Fig. 7 for the same period and altitudes as in Randel et al. (2012).

The left panels show the monthly averages of the respective values. Qualitatively these agree fairly well with the ACE-FTS observations by Randel et al. (2012). The increase of HDO and therewith $\delta \mathrm{D}\left(\mathrm{H}_{2} \mathrm{O}\right)$ with altitude in the stratosphere is too weak, however. At $30 \mathrm{~km} \delta \mathrm{D}\left(\mathrm{H}_{2} \mathrm{O}\right)$ exhibits values below $-600 \%$, while in the ACE-FTS retrieval values of around $-500 \%$ can be seen. Similarly to the comparison with the MIPAS retrieval, also the lower stratosphere in EMAC is drier in $\mathrm{H}_{2} \mathrm{O}$ and in HDO. Still, a clear tape recorder signal can be observed in all three panels, with min- imum values in the lower stratosphere during boreal winter and maxima during boreal summer.

For the right panels, the EMAC data have been filtered, using only the 4 months (February, April, August and October) which are also available in the ACE-FTS retrieval, to estimate the influence of the sparse temporal sampling on the tape recorder signals. This filtering somewhat blurs the tape recorder in all three panels, compared to the full data set. In particular, the tape recorder in $\delta \mathrm{D}\left(\mathrm{H}_{2} \mathrm{O}\right)$ appears to lose some of its upward motion at around $20 \mathrm{~km}$ and generally becomes less obvious. Therefore, it can be assumed that the sparse temporal sampling of ACE-FTS data is an issue in the evaluation of the $\delta \mathrm{D}\left(\mathrm{H}_{2} \mathrm{O}\right)$ tape recorder and may well contribute to the indistinctness of the signal in the study by Randel et al. (2012).

Due to its instrumental design, the SMR satellite instrument measures $\mathrm{H}_{2} \mathrm{O}$ and $\mathrm{HDO}$ orbitally shifted. This means that $\mathrm{H}_{2} \mathrm{O}$ and $\mathrm{HDO}$ are never measured at the same time and implies inaccuracies for the calculation of $\delta \mathrm{D}\left(\mathrm{H}_{2} \mathrm{O}\right)$. A comparison of the $\delta \mathrm{D}\left(\mathrm{H}_{2} \mathrm{O}\right)$ tape recorder signal between EMAC and SMR has therefore not been conducted.

\subsection{Summary and discussion}

The results of the EMAC simulations were first assessed with respect to the isotope ratios in precipitation, in order to en- 

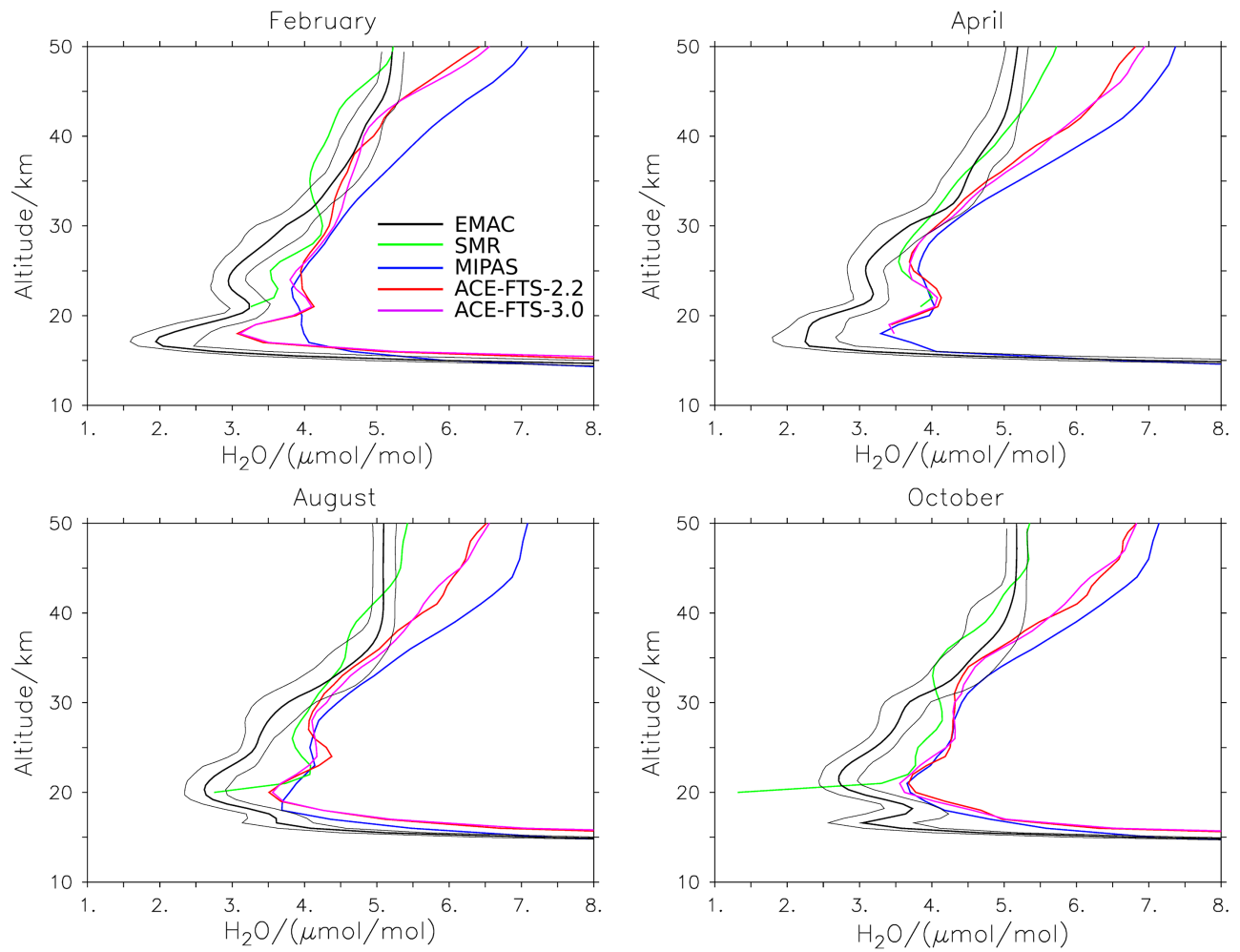

Figure 5. Comparison of $\mathrm{H}_{2} \mathrm{O}$ mixing ratio-altitude profiles between EMAC and various satellite observations. Black: averages, minima and maxima of 21 monthly averages of the EMAC simulation for the respective months; green: Odin/SMR; blue: ENVISAT/MIPAS; red: SCISAT/ACE-FTS-2.2; purple: SCISAT/ACE-FTS-3.0.

sure the correct representation of the physical processes in the troposphere. The EMAC results agree very well with GNIP (IAEA, 2009) data and are almost identical with results from the ECHAM5-wiso (Werner et al., 2011) model. Hence the physical processes and fractionation effects of the water isotopologues in the hydrological cycle of EMAC are represented satisfactorily (see the Supplement).

The chemical HDO precursor $\mathrm{CH}_{3} \mathrm{D}$ in the stratosphere was evaluated next. Here, a good qualitative agreement with chemically elaborate transport models by Ridal et al. (2001) and Ridal and Siskind (2002), as well as with balloon flights by Röckmann et al. (2011) is achieved. Differences in the model dynamics as well as in the fractionation coefficients can contribute to disagreements between the model results. The coarse horizontal resolution of the model, the possible drift of the balloon and associated local meteorological features and especially the sparsity of the measurements are the main issues in the comparison of $\delta \mathrm{D}\left(\mathrm{CH}_{4}\right)$ in EMAC with observations.

As desired by Röckmann et al. (2011), this modelling approach can assist further studies, especially concerning the investigation of the isotope effects of the chemical sink reactions of methane isotopologues. For instance, Kaiser et al. (2002) and Röckmann et al. (2003) discuss the application of apparent rather than laboratory-based fractionation fac- tors $\left(\mathrm{KIE}_{\mathrm{app}}=\sqrt{\mathrm{KIE}}\right)$ for long-lived trace gases that are removed in the stratosphere. While in the EMAC simulation the laboratory-based fractionation factors lead to very good agreement with measurements, according to Röckmann et al. (2001) turbulent diffusion and mixing of air masses lead to significantly smaller fractionation factors. Anyhow, more extensive measurements are desired for further evaluation of the methane isotope ratios in the stratosphere.

The mixing ratios of $\mathrm{HDO}$ and $\mathrm{H}_{2} \mathrm{O}$ were compared with the results of satellite retrievals. Inconsistencies between the individual satellite retrievals (see Lossow et al., 2011) render it difficult to define a distinct result. In the UTLS, the HDO profiles of EMAC agree well with the SMR satellite observations, but the $\mathrm{H}_{2} \mathrm{O}$ retrieval of SMR only reaches down to around $20 \mathrm{~km}$. Compared to the ACE-FTS and the MIPAS satellite profiles retrieved from measurements in the midinfrared, the UTLS appears to be too dry in $\mathrm{H}_{2} \mathrm{O}$ and in $\mathrm{HDO}$ in the EMAC model. Since for $\mathrm{H}_{2} \mathrm{O}$ this dry bias has already been discussed (see Jöckel et al., 2006) and HDO is, at first order, determined by $\mathrm{H}_{2} \mathrm{O}$, this dry bias for HDO is not surprising. Reasons for this are the slightly too cold hygropause in the nudging data (see e.g. Liu et al., 2010) and the coarse horizontal resolution of the model. However, due to the rather low vertical resolution of the satellite observations, the hygropause is blurred in the retrievals, and therefore $\mathrm{H}_{2} \mathrm{O}$ as 

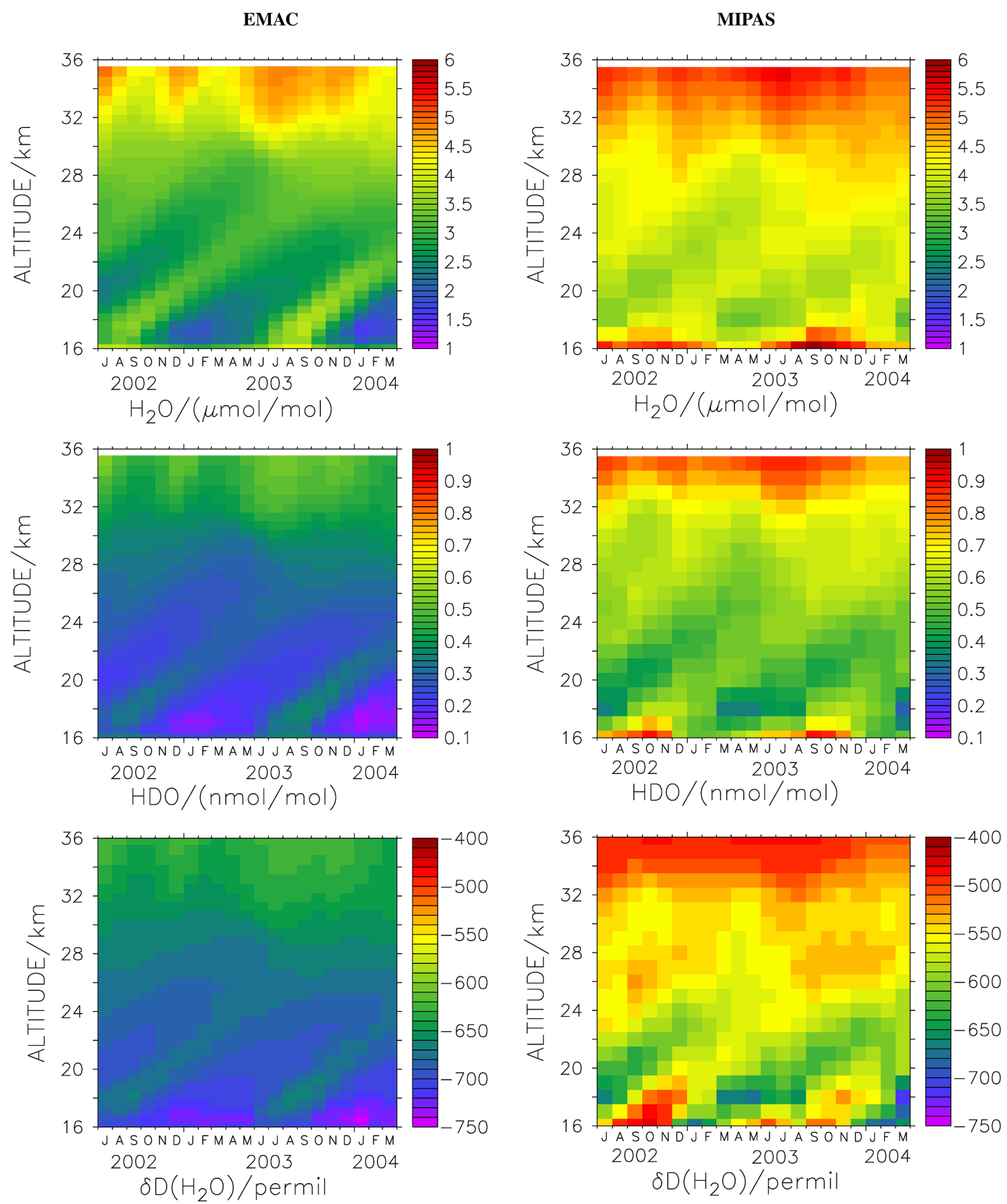

Figure 6. Altitude-time diagrams of $\mathrm{H}_{2} \mathrm{O}, \mathrm{HDO}$ and $\delta \mathrm{D}\left(\mathrm{H}_{2} \mathrm{O}\right)$ in the Tropics $\left(15^{\circ} \mathrm{S}-15^{\circ} \mathrm{N}\right)$. Left: EMAC simulation, right: MIPAS observations.

well as HDO is overestimated in MIPAS (see e.g. Steinwagner et al., 2007).

For $\mathrm{H}_{2} \mathrm{O}$, this offset weakens between 30 and $40 \mathrm{~km}$ and becomes stronger again further above. At around $35 \mathrm{~km}$, the simulated $\mathrm{H}_{2} \mathrm{O}$ increases more strongly with altitude than the satellite observations show. Above $40 \mathrm{~km}$, simulated $\mathrm{H}_{2} \mathrm{O}$ increases at much smaller rates compared to the satellite observations. These inconsistencies are most likely caused by the simplified methane oxidation scheme, since they are ob- vious during all 4 months where observations of ACE-FTS are available.

HDO in contrast shows a too weak increase with altitude from around $30 \mathrm{~km}$ upwards. Largely, this is attributable to the lack of the intermediate reactions containing HD in the $\mathrm{CH}_{3} \mathrm{D}$ oxidation chain in the model. Although we accounted for the deuterium storage in HD (using a relation by McCarthy et al., 2004), the isotope effects of the intermediate reactions on HDO are not taken into account in the model. As has been shown by Rahn et al. (2003) and Röckmann 

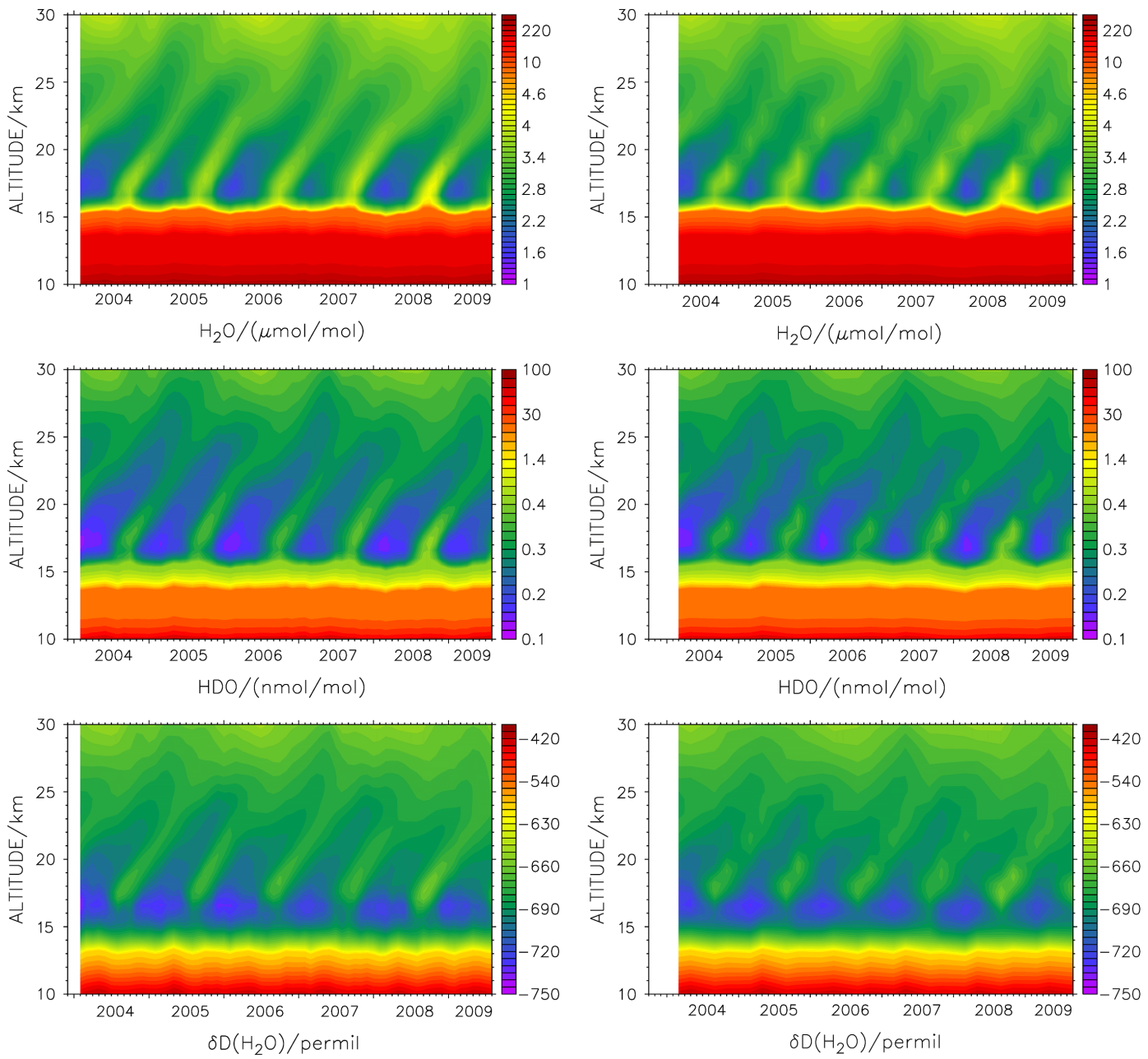

Figure 7. Altitude-time diagrams of $\mathrm{H}_{2} \mathrm{O}, \mathrm{HDO}$ and $\delta \mathrm{D}\left(\mathrm{H}_{2} \mathrm{O}\right)$ in the Tropics $\left(15^{\circ} \mathrm{S}-15^{\circ} \mathrm{N}\right)$ from the EMAC simulation. Left: monthly averages; right: averages of only February, April, August and October, as in Randel et al. (2012). The plotting algorithm linearly interpolates between the available months.

et al. (2003), stratospheric $\delta \mathrm{D}\left(\mathrm{H}_{2}\right)$ increases with altitude, while the mixing ratios of molecular hydrogen are rather constant. The conversion of isotopically very heavy molecular hydrogen to water would therefore increase the HDO mixing ratios strongly, while leaving $\mathrm{H}_{2} \mathrm{O}$ largely unaffected. Additionally, the influence of the oxidation of $\mathrm{CH}_{3} \mathrm{D}$ itself also increases with altitude. This implies that the importance of the intermediate reaction with HD on HDO, which is not considered here, increases with altitude too. Our simplifications can therefore explain the offset in HDO mixing ratios between the EMAC simulation and the satellite retrievals and the different behaviour of $\mathrm{H}_{2} \mathrm{O}$ and $\mathrm{HDO}$. This leads to too low $\delta \mathrm{D}\left(\mathrm{H}_{2} \mathrm{O}\right)$ values in the upper parts of the stratosphere

In future studies, the chemical deficiencies of the H2OISO submodel can be reduced by including an explicit representation of HD to take into account the intermediate reactions from $\mathrm{CH}_{3} \mathrm{D}$ to HDO. However, according to Zahn et al. (2006) the reaction rates of HD and especially the fractiona- tion effects of these reactions are poorly quantified and hence can be subject to large uncertainties. As an alternative, however more sophisticated modelling approach, the water isotopologues can be included in the isotope scheme of Gromov et al. (2010), by extending it to the deuterium cycle. This features a number of isotopic species and reactions, which also affect the hydrogen reactions.

The tape recorder signals of $\mathrm{H}_{2} \mathrm{O}, \mathrm{HDO}$ and $\delta \mathrm{D}\left(\mathrm{H}_{2} \mathrm{O}\right)$ of the EMAC simulation were compared to the MIPAS retrieval (see Steinwagner et al., 2007, 2010). In the lower stratosphere, EMAC and MIPAS are closest during winter, where the differences can mostly be explained with the low vertical resolution of the MIPAS sampling. The summer months, however, show much stronger deviations between model and observations, with too low values in all quantities in the simulation, especially in $\mathrm{HDO}$ and $\delta \mathrm{D}\left(\mathrm{H}_{2} \mathrm{O}\right)$. This suggests deficiencies in the model physics, for example the underrepresentation of overshooting convection in the convection 
scheme (Tiedtke-Nordeng; Tiedtke, 1989; Nordeng, 1994) applied here. According to the studies by Dessler et al. (2007) and Bolot et al. (2013) a more complete representation of this effect can enhance the mixing ratios of $\mathrm{HDO}$, while $\mathrm{H}_{2} \mathrm{O}$ is hardly affected. This would increase $\delta \mathrm{D}\left(\mathrm{H}_{2} \mathrm{O}\right)$ in the UTLS especially during $\mathrm{NH}$ summer, since convective events are more frequent during that time of the year. Thus, a better representation of the $\delta \mathrm{D}\left(\mathrm{H}_{2} \mathrm{O}\right)$ tape recorder in the model could be achieved. However, the inconsistent vertical resolutions between $\mathrm{H}_{2} \mathrm{O}$ and $\mathrm{HDO}$ in the MIPAS retrieval may be the reason for a spurious amplification of the $\delta \mathrm{D}\left(\mathrm{H}_{2} \mathrm{O}\right)$ tape recorder signal in the observations (Orbe et al., 2013). The correction of this artefact in the MIPAS data is subject of current investigations and may also lead to a better agreement between the EMAC and MIPAS amplitudes of the $\delta \mathrm{D}\left(\mathrm{H}_{2} \mathrm{O}\right)$ tape recorders.

The influence of convective ice lofting on the isotopic composition of stratospheric water vapour in this simulation is analysed in the companion part 2 paper (Eichinger et al., 2015). In future studies, the quality of other convection schemes could be tested with respect to the results of HDO in the UTLS and a possibly better representation of overshooting convection. This, however, requires the implementation of the water isotopologues in the alternative convection schemes.

The phase shift of 2 to 3 months between the tape recorders of MIPAS and EMAC, which can be observed in all three quantities, is not easily explainable. Due to the coarse vertical resolution of the MIPAS retrieval there might be a delay in the retrieved tape recorder signals of up to 1 month. There is no evidence that the seasonality of convection in EMAC is phase shifted. Simulated patterns of moisture in the UTLS compare well with observations and analyses of the seasonal cycle of zonal mean precipitation (convective and large-scale clouds) and integrated water vapour conducted by Hagemann et al. (2006) and Tost et al. (2006) also show accordance with observations.

The seasonal cycle of lower stratospheric $\delta \mathrm{D}\left(\mathrm{H}_{2} \mathrm{O}\right)$ in the ACE-FTS retrieval (see Randel et al., 2012) shows a different behaviour than that of the MIPAS retrieval and the EMAC simulation. The too low $\delta \mathrm{D}\left(\mathrm{H}_{2} \mathrm{O}\right)$ values in EMAC compared to ACE-FTS, especially during summer and in the upper stratosphere, are consistent; however, Randel et al. (2012) did not find the tape recorder signal in $\delta \mathrm{D}\left(\mathrm{H}_{2} \mathrm{O}\right)$. The $\delta \mathrm{D}\left(\mathrm{H}_{2} \mathrm{O}\right)$ tape recorder in EMAC is weaker than the corresponding signals in $\mathrm{H}_{2} \mathrm{O}$ and HDO. Still, the pattern is clearly recognisable. A possible reason for the lack of the upward propagation of the seasonal cycle of $\delta \mathrm{D}\left(\mathrm{H}_{2} \mathrm{O}\right)$ in the ACE-FTS observations is the sparse temporal sampling of the instrument in the Tropics. A filtering of the EMAC data to the sampling reduces the apparent temporal upward motion of the $\delta \mathrm{D}\left(\mathrm{H}_{2} \mathrm{O}\right)$ tape recorder in the UTLS between around 17 and $20 \mathrm{~km}$. Since $\delta \mathrm{D}\left(\mathrm{H}_{2} \mathrm{O}\right)$ does not increase strongly enough with altitude in the EMAC simulation due to the incomplete chemistry, a weaker $\delta \mathrm{D}\left(\mathrm{H}_{2} \mathrm{O}\right)$ tape recorder signal is expected for the correction of this effect. This would blur the tape recorder signal in EMAC above $20 \mathrm{~km}$ and therewith suppress its upward propagation. Below around $25 \mathrm{~km}$, however, the chemical influence is very weak and thus some tape recorder signal will remain. The effect of methane oxidation on the $\delta \mathrm{D}\left(\mathrm{H}_{2} \mathrm{O}\right)$ tape recorder is analysed more deeply in the companion part 2 paper.

For more quantitative comparisons between models and observations, more sophisticated methods will be applied in future evaluations. The vertical resolution of the EMAC data can be transformed to the resolution of the respective satellite retrieval using their averaging kernels. Also, the cloud filtering methods used for the satellite data can be applied to the model data. This elaborate evaluation can possibly assist to reduce the discrepancies between model results and observations and reveal the model and the measurement insufficiencies more precisely. In the present and in the companion (part 2) study, however, a more comprehensive understanding of the $\delta \mathrm{D}\left(\mathrm{H}_{2} \mathrm{O}\right)$ tape recorder is desired, which can best be achieved with the complete data record.

\section{Conclusions}

The EMAC model system has been extended with the submodel H2OISO, which contains a separate hydrological cycle, comprising the water isotopologues $\mathrm{HDO}$ and $\mathrm{H}_{2}{ }^{18} \mathrm{O}$ and their physical fractionation effects. The good agreement with measurement data and the ECHAM5-wiso model leads to the conclusion that this expanded model system represents the state of the art of water isotopologue-enabled atmosphere GCMs. Moreover, a parameterisation of the oxidation of $\mathrm{CH}_{3} \mathrm{D}$ was included to the H2OISO submodel. The sink reactions of $\mathrm{CH}_{3} \mathrm{D}$, which include reaction- and partly temperature-dependent kinetic fractionation effects, determine the chemical production of HDO. This rather simple parameterisation for the methane isotopologue $\mathrm{CH}_{3} \mathrm{D}$ is apparently quite robust and can be applied for further studies concerning the isotopic composition of methane in the stratosphere. The comparison of stratospheric HDO profiles with satellite observations reveals a qualitatively good agreement. However, systematic discrepancies can be observed. These can be associated with uncertainties in the convection scheme, the simplified representation of methane oxidation and, especially in the upper stratosphere, the negligence of the fractionation effects involving molecular hydrogen. The comparison of the stratospheric tape recorder signal in $\mathrm{H}_{2} \mathrm{O}$, $\mathrm{HDO}$ and $\delta \mathrm{D}\left(\mathrm{H}_{2} \mathrm{O}\right)$ between EMAC and satellite observations is difficult. Considering all the uncertainties in the measurements and in the model, the overall representations of the tape recorder signals in EMAC are reasonable. The $\delta \mathrm{D}\left(\mathrm{H}_{2} \mathrm{O}\right)$ tape recorder simulated by EMAC at least partly resolves the discrepancies between the divergent conclusions from the MIPAS and the ACE-FTS satellite retrievals. The EMAC $\delta \mathrm{D}\left(\mathrm{H}_{2} \mathrm{O}\right)$ tape recorder ranges between 
the pronounced tape recorder from MIPAS and the missing upward propagation of the seasonal signal in ACE-FTS observations. The revisions of the individual insufficiencies of the retrievals and the model, however, are expected to generate more compatible results. Despite the quantitative differences in stratospheric $\delta \mathrm{D}\left(\mathrm{H}_{2} \mathrm{O}\right)$ between EMAC and satellite observations, the conclusion can be drawn that the new MESSy submodel H2OISO, used in the framework of the EMAC model, provides the possibility to attain additional insights into the mechanisms which control the stratospheric water vapour budget. The physical and chemical properties of the isotopic composition of water make possible new investigations, with respect to the processes and pathways which control the stratospheric water vapour budget. The $\mathrm{H} 2 \mathrm{OISO}$ submodel will be available in future EMAC versions as an additional option for all users. 


\section{Appendix A: Applied MESSy submodels}

CLOUD: $\quad$ Original cloud and cover routines from ECHAM5 as MESSy submodel (Roeckner et al., 2006, and references therein).

CONVECT: This submodel calculates the process of Convection. It consists of an interface to choose different convection schemes and the calculations themselves (Tost et al., 2006).

CVTRANS: The Convective Tracer Transport submodel calculates the transport of tracers due to convection. It uses a monotonic, positive definite and mass conserving algorithm following the bulk approach (Tost, 2006).

GWAVE: Hines non-orographic gravity wave routines from ECHAM5 as MESSy submodel (Roeckner et al., 2006).

RAD4ALL: $\quad$ ECHAM5 radiation scheme as MESSy submodel (Roeckner et al., 2006; Jöckel et al., 2006).

TROPOP: $\quad$ Submodel for Tropopause (WMO + PV) and other diagnostics (Jöckel et al., 2006).

JVAL: $\quad$ This submodel is for fast online calculation of $\mathbf{J}$-values (photolysis rate coefficients) using cloud water content and cloudiness calculated by the base model and/or climatological ozone and climatological aerosol (see Landgraf and Crutzen, 1998; Sander et al., 2014).

TNUDGE: The submodel "Tracer Nudg(e)ing" is used for Newtonian relaxation of user-defined tracers as pseudoemissions (Kerkweg et al., 2006). 


\section{The Supplement related to this article is available online at doi:10.5194/acp-15-5537-2015-supplement.}

Acknowledgements. The authors thank the DFG (Deutsche Forschungsgemeinschaft) for funding the research group SHARP (Stratospheric Change and its Role for Climate Prediction, DFG Research Unit 1095); the presented study was conducted as part of R. Eichinger's PhD thesis under grant number BR 1559/5-1. We acknowledge support from the Leibnitz Supercomputing Centre (LRZ), the German Climate Computing Centre (DKRZ) and all MESSy developers and submodel maintainers. Furthermore we thank T. Röckmann for providing the $\mathrm{CH}_{3} \mathrm{D}$ balloon data and C. Kiemle as well as two anonymous referees for valuable comments on the paper.

The article processing charges for this open-access publication were covered by a Research

Centre of the Helmholtz Association.

Edited by: P. Haynes

\section{References}

Bolot, M., Legras, B., and Moyer, E. J.: Modelling and interpreting the isotopic composition of water vapour in convective updrafts, Atmos. Chem. Phys., 13, 7903-7935, doi:10.5194/acp-13-79032013, 2013.

Brass, M. and Röckmann, T.: Continuous-flow isotope ratio mass spectrometry method for carbon and hydrogen isotope measurements on atmospheric methane, Atmos. Meas. Tech., 3, 17071721, doi:10.5194/amt-3-1707-2010, 2010.

Craig, H. and Gordon, L. I.: Stable Isotopes in Oceanographic Studies and Paleotemperatures, chapter Deuterium and oxygen 18 variations in the ocean and the marine atmosphere, 9-130, V. Lischi, Pisa, Italy, 1965.

Dansgaard, W.: Stable isotopes in precipitation, Tellus, 16, 436468, 1964

Dee, D. P., Uppala, S. M., Simmons, A. J., Berrisford, P., Poli, P., Kobayashi, S., Andrae, U., Balmaseda, M. A., Balsamo, G., Bauer, P., Bechtold, P., Beljaars, A. C. M., van de Berg, L., Bidlot, J., Bormann, N. B., Delsol, C., Dragani, R., Fuentes, M., Geer, A. J., Haimberger, L., Healy, S. B., Hersbach, H., Hólm, E. V., Isaksen, L., Kållberg, P., Köhler, M., Matricardi, M., McNally, A. P., Monge-Sanz, B. M., Morcrette, J.-J., Park, B.-K., Peubey, C., de Rosnay, P., Tavolato, C., Thépaut, J.-N., and Vitart, F.: The ERA-Interim reanalysis: configuration and performance of the data assimilation system, Q. J. Roy. Meteorol. Soc., 656, 553-597, 2011.

Dessler, A. E., Hanisco, T. F., and Füglistaler, S.: Effects of convective ice lofting on $\mathrm{H} 2 \mathrm{O}$ and $\mathrm{HDO}$ in the tropical tropopause layer, J. Geophys. Res.-Atmos., 112, D18309, doi:10.1029/2007JD008609, 2007.

Eichinger, R., Jöckel, P., and Lossow, S.: Simulation of the isotopic composition of stratospheric water vapour - Part 2: Investigation of $\mathrm{HDO} / \mathrm{H}_{2} \mathrm{O}$ variations, Atmos. Chem. Phys., in press, 2015.
Füglistaler, S., Dessler, A. E., Dunkerton, J. T., Folkins, I., Fu, Q., and Mote, P. W.: Tropical Tropopause Layer, Rev. Geophys., 47, RG1004, doi:10.1029/2008RG000267, 2009.

Gettelman, A. and Kinnison, D. E.: Impact of monsoon circulations on the upper troposphere and lower stratosphere, J. Geophys. Res., 109, D22101, doi:10.1029/2004JD004878, 2004.

Gromov, S., Jöckel, P., Sander, R., and Brenninkmeijer, C. A. M.: A kinetic chemistry tagging technique and its application to modelling the stable isotopic composition of atmospheric trace gases, Geosci. Model Dev., 3, 337-364, doi:10.5194/gmd-3-337-2010, 2010.

Hagemann, R., Nief, G., and Roth, E.: Absolute isotopic scale for deuterium analysis of natural waters, Absolute $\mathrm{D} / \mathrm{H}$ ratio for SMOW, Tellus, 22, 712-715, 1970.

Hagemann, S., Arpe, K., and Roeckner, E.: Evaluation of the Hydrological Cycle in the ECHAM5 Model, J. Climate, 19, 38103827, 2006.

Hoffmann, G., Werner, M., and Heimann, M.: Water isotope module of the ECHAM atmospheric general circulation model: A study on timescales from days to several years, J. Geophys. Res., 103, 16871-16896, 1998.

IAEA: Reference Sheet for VSMOW2 and SLAP2 international measurement standards, Issued 2009-02-13, International Atomic Energy Agency, Vienna, p. 5, http://curem. iaea.org/catalogue/SI/pdf/VSMOW2_SLAP2.pdf (last access: 13 May 2015), 2009.

Irion, F. W., Moyer, E. J., Gunson, M. R., Rinsland, C. P., Yung, Y. L., Michelsen, H. A., Salawitch, R. J., Chang, A. Y., Newchurch, M. J., Abbas, M. M., Abrams, M. C., and Zander, R.: Stratospheric observations of $\mathrm{CH}_{3} \mathrm{D}$ and HDO from ATMOS infrared solar spectra: Enrichments of deuterium in methane and implications for HD, Geophys. Res. Lett., 23, 2381-2384, 1996.

Jöckel, P., Sander, R., Kerkweg, A., Tost, H., and Lelieveld, J.: Technical Note: The Modular Earth Submodel System (MESSy) - a new approach towards Earth System Modeling, Atmos. Chem. Phys., 5, 433-444, doi:10.5194/acp-5-433-2005, 2005.

Jöckel, P., Tost, H., Pozzer, A., Brühl, C., Buchholz, J., Ganzeveld, L., Hoor, P., Kerkweg, A., Lawrence, M. G., Sander, R., Steil, B., Stiller, G., Tanarhte, M., Taraborrelli, D., van Aardenne, J., and Lelieveld, J.: The atmospheric chemistry general circulation model ECHAM5/MESSy1: consistent simulation of ozone from the surface to the mesosphere, Atmos. Chem. Phys., 6, 50675104, doi:10.5194/acp-6-5067-2006, 2006.

Jöckel, P., Kerkweg, A., Buchholz-Dietsch, J., Tost, H., Sander, R., and Pozzer, A.: Technical Note: Coupling of chemical processes with the Modular Earth Submodel System (MESSy) submodel TRACER, Atmos. Chem. Phys., 8, 1677-1687, doi:10.5194/acp8-1677-2008, 2008.

Jöckel, P., Kerkweg, A., Pozzer, A., Sander, R., Tost, H., Riede, H., Baumgaertner, A., Gromov, S., and Kern, B.: Development cycle 2 of the Modular Earth Submodel System (MESSy2), Geosci. Model Dev., 3, 717-752, doi:10.5194/gmd-3-717-2010, 2010.

Johnson, D. G., Jucks, K. W., Traub, W. A., and Chance, K. V.: Isotopic composition of stratospheric water vapor: Implications for transport, J. Geophys. Res., 106, 12219-12226, 2001.

Kaiser, J., Brenninkmeijer, C. A. M., and Röckmann, T.: Intramolecular $15 \mathrm{~N}$ and $18 \mathrm{O}$ fractionation in the reaction of $\mathrm{N} 2 \mathrm{O}$ with $\mathrm{O}(1 \mathrm{D})$ and its implications for the stratospheric 
N2O isotope signature, J. Geophys. Res., 107, D14,4214, doi:10.1029/2001JD001506, 2002.

Kerkweg, A., Sander, R., Tost, H., and Jöckel, P.: Technical note: Implementation of prescribed (OFFLEM), calculated (ONLEM), and pseudo-emissions (TNUDGE) of chemical species in the Modular Earth Submodel System (MESSy), Atmos. Chem. Phys., 6, 3603-3609, doi:10.5194/acp-6-3603-2006, 2006.

Khaykin, S., Pommereau, J.-P., Korshunov, L., Yushkov, V., Nielsen, J., Larsen, N., Christensen, T., Garnier, A., Lukyanov, A., and Williams, E.: Hydration of the lower stratosphere by ice crystal geysers over land convective systems, Atmos. Chem. Phys., 9, 2275-2287, doi:10.5194/acp-9-2275-2009, 2009.

Landgraf, J. and Crutzen, P. J.: An Efficient Method for Online Calculations of Photolysis and Heating Rates, J. Atmos. Sci., 55, 863-878, 1998.

LeGrande, A. N. and Schmidt, G. A.: Global gridded data set of the oxygen isotopic composition in seawater, Geophys. Res. Lett., 33, L12604, doi:10.1029/2006GL026011, 2006.

Lin, S. J. and Rood, R. B.: Multidimensional flux form semilagrangian transport, Mon. Weather Rev., 124, 2046-2068, 1996.

Liu, Y. S., Fueglistaler, S., and Haynes, P. H.: Advectioncondensation paradigm for stratospheric water vapor, J. Geophys. Res., 115, D24307, doi:10.1029/2010JD014352, 2010.

Lossow, S., Steinwagner, J., Urban, J., Dupuy, E., Boone, C. D., Kellmann, S., Linden, A., Kiefer, M., Grabowski, U., Glatthor, N., Höpfner, M., Röckmann, T., Murtagh, D. P., Walker, K. A., Bernath, P. F., von Clarmann, T., and Stiller, G. P.: Comparison of HDO measurements from Envisat/MIPAS with observations by Odin/SMR and SCISAT/ACE-FTS, Atmos. Meas. Tech., 4, 1855-1874, doi:10.5194/amt-4-1855-2011, 2011.

McCarthy, M. C., Boering, K. A., Rahn, T., Eiler, J. M., Rice, A. L., Tyler, S. C., Schauffler, S., Atlas, E., and Johnson, D. G.: The hydrogen isotopic composition of water vapor entering the stratosphere inferred from high-precision measurements of $\delta \mathrm{D}-\mathrm{CH}_{4}$ and $\delta \mathrm{D}-\mathrm{H}_{2}$, J. Geophys. Res., 109, D07304, doi:10.1029/2003JD004003, 2004.

Mote, P., Rosenlof, K., Mclntyre, M., Carr, E., Gille, J., Holton, J., Kinnersley, J., Pumphrey, H., Russel, J., and Waters, J.: An atmospheric tape recorder: The imprint of tropical tropopause temperatures on stratospheric water vapor, J. Geophys. Res., 101, 39894006, 1996.

Nair, H., Summers, M. E., Miller, C. E., and Yung, Y. L.: Isotopic fractionation of methane in the martian atmosphere, Icarus, 175, 32-35, 2005.

Nassar, R., Bernath, P. F., Boone, C. D., Gettelman, A., McLeod, S. D., and Rinsland, C. P.: Variability in $\mathrm{HDO} / \mathrm{H}_{2} \mathrm{O}$ abundance ratios in the tropical tropopause layer, J. Geophys. Res., 112, D21305, doi:10.1029/2007JD008417, 2007.

Nixon, C. A., Temelso, B., Vinatier, S., Teanby, N. A., Bézard, B., Achterberg, R. K., Mandt, K. E., Sherrill, C. D., Irwin, P. G. J., Jennings, D. E., Romani, P. N., Coustenis, A., and Flasar, F. M.: Isotopic ratios in Titan's methane: Measurements and Modelling, Astrophys. J., 749:159, doi:10.1088/0004637X/749/2/159, 2012.

Nordeng, T. E.: Extended version of the convection parameterization scheme at ECMWF and their impacts upon the mean climate and transient activity of the model in the tropics, Res. Dep. Tech Memo, 206, Eur. Cent. for Medium-Range Weather Forecast, Reading, Berkshire, UK, 41 pp., 1994.
Orbe, C., Garny, H., and Seviour, W.: SPARC Workshop on the Brewer-Dobson Circulation. SPARC Newsletter, No. 40:1121.2013

Plumb, R. A. and Ko, M. K. W.: Interrelationships between mixing ratios of long lived stratospheric constituents, J. Geophys. Res., 101, 3957-3972, 2004.

Rahn, T., Eiler, J. M., Boering, K. A., Wennberg, P. O., McCarthy, M. C., Tyler, S., Schauffler, S., Donnely, S., and Atlas, E.: Extreme deuterium enrichment in stratospheric hydrogen and the global atmospheric budget of $\mathrm{H}_{2}$, Nature, 424, 918-921, 2003.

Randel, W. J., Moyer, E., Park, M., Jensen, E., Bernath, P., Walker, K., and Boone, C.: Global variations of $\mathrm{HDO}$ and $\mathrm{HDO} / \mathrm{H}_{2} \mathrm{O}$ ratios in the upper troposphere and lower stratosphere derived from ACE-FTS satellite measurments, J. Geophys. Res., 117, D06303, doi:10.1029/2011JD016632, 2012.

Rhee, T. S., Brenninkmeijer, C. A. M., Braß, M., and Brühl, C.: Isotopic composition of $\mathrm{H}_{2}$ from $\mathrm{CH}_{4}$ oxidation in the stratosphere and the troposphere, J. Geophys. Res., 111, D23303, doi:10.1029/2005JD006760, 2006.

Ridal, M.: Isotopic ratios of water vapor and methane in the stratosphere: Comparison between ATMOS measurements and a one-dimensional model, J. Geophys. Res., 107, 4285, doi:10.1029/2001JD000708, 2002.

Ridal, M. and Siskind, D. E.: A two-dimensional suimulation of the isotopic composition of water vapor and methane in the upper atmosphere, J. Geophys. Res., 107, 4807, doi:10.1029/2002JD002215, 2002.

Ridal, M., Jonsson, A., Werner, M., and Murtagh, D. P.: A onedimensional simulation of the water vapor isotope HDO in the tropical stratosphere, J. Geophys. Res., 106, 32283-32294, 2001.

Risi, C., Bony, S., Vimeux, F., and Jouzel, J.: Water-stable isotopes in the LMDZ4 general circulation model: Model evaluation for present-day and past climates and applications to climatic interpretations of tropical isotopic records, J. Geophys. Res., 115, D12118, doi:10.1029/2009JD013255, 2010.

Röckmann, T., Kaiser, J., Brenninkmeijer, C. A. M., Crowley, J. N., Borchers, R., Brand, W. A., and Crutzen, P. J.: Isotopic enrichment of nitrous oxide $\left({ }^{15} \mathrm{~N}^{14} \mathrm{~N}^{16} \mathrm{O},{ }^{14} \mathrm{~N}^{15} \mathrm{~N}^{16} \mathrm{O}\right.$ and ${ }^{14} \mathrm{~N}^{14} \mathrm{~N}^{18} \mathrm{O}$ ) in the stratosphere and in the laboratory, J. Geophys. Res., 106, 10403-10410, 2001.

Röckmann, T., Rhee, T. S., and Engel, A.: Heavy hydrogen in the stratosphere, Atmos. Chem. Phys., 3, 2015-2023, doi:10.5194/acp-3-2015-2003, 2003.

Röckmann, T., Brass, M., Borchers, R., and Engel, A.: The isotopic composition of methane in the stratosphere: high-altitude balloon sample measurements, Atmos. Chem. Phys., 11, 13287-13304, doi:10.5194/acp-11-13287-2011, 2011.

Roeckner, E., Bäuml, G., Bonaventura, L., Brokopf, R., Esch, M., Giorgetta, M., Hagemann, S., Kirchner, I., Kornblueh, L., Manzini, E., Rhodin, A., Schlese, U., Schulzweida, U., and Tompkins, A.: The atmospheric general circulation model ECHAM 5. PART I: Model description, Max-Planck-Institut für Meteorologie, Hamburg, Report No. 349, 2003.

Roeckner, E., Brokopf, R., Esch, M., Giorgetta, M., Hagemann, S., Kornblueh, L., Manzini, E., Schlese, U., and Schulzweida, U.: Sensitivity of simulated climate to horizontal and vertical resolution in the ECHAM5 atmosphere model, J. Climate, 19, 37713791, 2006. 
Sander, R., Jöckel, P., Kirner, O., Kunert, A. T., Landgraf, J., and Pozzer, A.: The photolysis module JVAL-14, compatible with the MESSy standard, and the JVal PreProcessor (JVPP), Geosci. Model Dev., 7, 2653-2662, doi:10.5194/gmd-7-26532014, 2014.

Saueressig, G., Bergamaschi, P., Crowley, J., Fischer, H., and Harris, $\mathrm{G} .: \mathrm{D} / \mathrm{H}$ kinetic isotope effects in the reaction $\mathrm{CH}_{4}+\mathrm{Cl}$, Geophys. Res. Lett., 23, 3619-3622, 1996.

Saueressig, G., Crowley, J., Bergamaschi, P., Brühl, C., Brenninkmeijer, C., and Fischer, H.: Carbon 13 and D kinetic isotope effects in the reactions of $\mathrm{CH}_{4}$ with $\mathrm{O}\left({ }^{1} \mathrm{D}\right)$ and $\mathrm{OH}$ : New laboratory measurements and their implications for the isotopic composition of stratospheric methane, J. Geophys. Res., 106, $23127-$ 23138, 2001.

Schmidt, G. A., Hoffmann, G., Shindell, D. T., and Hu, Y.: Modeling atmospheric stable water isotopes and the potential for constraining cloud processes and stratospheretroposphere water exchange, J. Geophys. Res., 110, D21314, doi:10.1029/2005JD005790, 2005.

Solomon, S., Rosenlof, K. H., Portmann, R. W., Daniel, J. S., Davis, S. M., Sanford, T. J., and Plattner, G.-K.: Contributions of Stratospheric Water Vapor to Decadal Changes in the Rate of Global Warming, Science, 327, 1219-1223, 2010.

Steinwagner, J., Milz, M., von Clarmann, T., Glatthor, N., Grabowski, U., Höpfner, M., Stiller, G. P., and Röckmann, T.: HDO measurements with MIPAS, Atmos. Chem. Phys., 7, 26012615, doi:10.5194/acp-7-2601-2007, 2007.

Steinwagner, J., Füglistaler, S., Stiller, G., von Clarmann, T., Kiefer, M., Borsboom, P.-P., van Delden, A., and Röckmann, T.: Tropical dehydration processes constrained by the seasonality of stratospheric deuterated water, Nat. Geosci., 3, 262-266, 2010.

Stenke, A. and Grewe, V.: Simulation of stratospheric water vapor trends: impact on stratospheric ozone chemistry, Atmos. Chem. Phys., 5, 1257-1272, doi:10.5194/acp-5-1257-2005, 2005.
Tiedtke, M.: A comprehensive mass flux scheme for cumulus parameterization in large-scale models, Mon. Weather Rev., 117, 1779-1800, 1989.

Tost, H.: Global Modelling of Cloud, Convection and Precipitation Influences on Trace Gases and Aerosols, $\mathrm{PhD}$ thesis, University of Bonn, Germany, 2006.

Tost, H., Jöckel, P., and Lelieveld, J.: Influence of different convection parameterisations in a GCM, Atmos. Chem. Phys., 6, 54755493, doi:10.5194/acp-6-5475-2006, 2006.

Umezawa, T., Machida, T., Ishijima, K., Matsueda, H., Sawa, Y., Patra, P. K., Aoki, S., and Nakazawa, T.: Carbon and hydrogen isotopic ratios of atmospheric methane in the upper troposphere over the Western Pacific, Atmos. Chem. Phys., 12, 8095-8113, doi:10.5194/acp-12-8095-2012, 2012.

Urban, J., Lautié, N., Murtagh, D., Eriksson, P., Kasai, Y., Lossow, S., Dupuy, E., de La Noë, J., Frisk, U., Olberg, M., Le Flochmoën, E., and Ricaud, P.: Global observations of middle atmospheric water vapour by the Odin satellite: An overview, Planet. Space Sci., 55, 1093-1102, 2007.

Werner, M., Heimann, M., and Hoffmann, G.: Isotopic composition and origin of polar precipitation in present and glacial climate simulations, Tellus B, 53B, 53-71, 2001.

Werner, M., Langebroek, P. M., Carlsen, T., Herold, M., and Lohmann, G.: Stable water isotopes in the ECHAM5 general circulation model: Toward high-resolution isotope modeling on a global scale, J. Geophys. Res., 116, D15109, doi:10.1029/2011JD015681, 2011.

Zahn, A., Franz, P., Bechtel, C., Grooß, J.-U., and Röckmann, T.: Modelling the budget of middle atmospheric water vapour isotopes, Atmos. Chem. Phys., 6, 2073-2090, doi:10.5194/acp-62073-2006, 2006. 